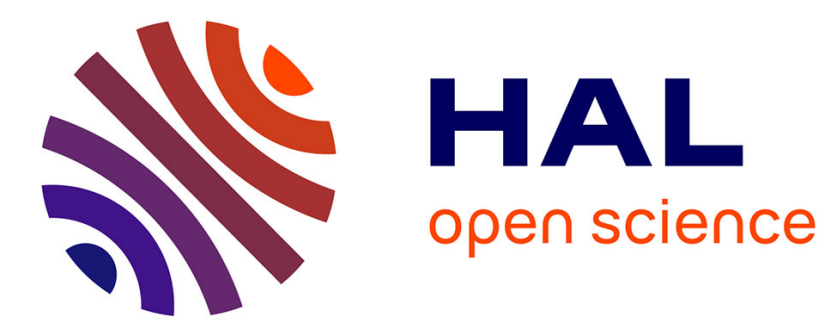

\title{
Finite element analysis of a prestressed mechanism with multi-antagonistic and hysteretic SMA actuation
}

\author{
R. Boufayed, F. Chapelle, J. F Destrebecq, Xavier Balandraud
}

\section{To cite this version:}

R. Boufayed, F. Chapelle, J. F Destrebecq, Xavier Balandraud. Finite element analysis of a prestressed mechanism with multi-antagonistic and hysteretic SMA actuation. Meccanica, 2020, 55 (5), pp.10071024. 10.1007/s11012-020-01155-9 . hal-03039261

\section{HAL Id: hal-03039261 \\ https://hal.uca.fr/hal-03039261}

Submitted on 3 Dec 2020

HAL is a multi-disciplinary open access archive for the deposit and dissemination of scientific research documents, whether they are published or not. The documents may come from teaching and research institutions in France or abroad, or from public or private research centers.
L'archive ouverte pluridisciplinaire HAL, est destinée au dépôt et à la diffusion de documents scientifiques de niveau recherche, publiés ou non, émanant des établissements d'enseignement et de recherche français ou étrangers, des laboratoires publics ou privés. 


\title{
Finite element analysis of a prestressed mechanism with multi-antagonistic and hysteretic SMA actuation
}

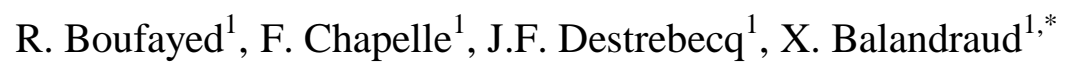

${ }^{1}$ Université Clermont Auvergne, CNRS, SIGMA Clermont, Institut Pascal, 63000 ClermontFerrand, France

*Corresponding author. Tel.: +33 4732880 89. Fax: +33 4732881 00. E-mail address: xavier.balandraud@sigma-clermont.fr

\begin{abstract}
This paper deals with the specific hysteretic effects of a multi-antagonistic shapememory alloy (SMA) actuation system in which each wire can be thermally activated individually (one or more at a time). A planar system with six SMA wires organized in a ternary rotational symmetry is studied numerically, via finite element calculation software. The objective is to analyze the functional characteristics of such mechanism, whose response during a thermal activation sequence is multi-antagonistic and hysteretic. Important points are highlighted, such as the avoidance of buckling and plasticity, the possibility of locking a configuration without energy input, and the "attraction" effect of any heating step on the following steps. The feasibility of reaching a given target in the workspace is also illustrated. Finally, the analysis shows the necessity to consider these multi-antagonistic and hysteretic aspects of the actuation in the future design and control of such type of mechanisms. The latter could be of interest as hollow shaft rotary actuators with additional (small) translation degrees of freedom in applications requiring long-term and stable positioning at ambient temperature.
\end{abstract}

Keyword: Shape-memory alloy; Prestressed mechanism; Multi-antagonistic actuation, Hysteretic behavior; Finite element simulation 


\section{Introduction}

New types of actuation are currently being studied to develop the next generation of mechanisms, in particular by employing smart materials [1-3]. The latter can change their shape or physical properties under the influence of external stimuli such as temperature, stress, magnetic or electric fields [4]. The use of smart materials enables more integrated and robust mechanism architectures, especially in high-constrained environments such as the biomedical field or robotics: see for instance Refs. [5, 6] and [7, 8] respectively. In particular, mechanisms driven by shape-memory alloys (SMAs) have attracted the interest of researchers because of their particular mechanical properties [9-14].

SMAs are active materials whose mechanical response is driven by temperature and stress. The underlying physical phenomenon is a solid-solid transition between two phases, namely austenite (A) and martensite (M) [15]. Roughly, austenite and martensite are present at "high" and "low" temperatures respectively. In the austenitic state, a SMA sample has a unique shape that was memorized during material manufacturing. In the martensitic state, the sample can be "permanently" deformed by several percent (pseudo-plasticity effect). A so-called one-way memory effect consists of heating the martensitic sample to activate the $M \rightarrow A$ transformation, leading to the recovery of the memorized shape. A two-way memory effect is possible if cooling is carried out under stress, which requires mechanical antagonism, by using a bias spring for instance. Note that a two-way memory effect at zero force or stress is possible after thermomechanical "training", consisting of numerous thermal cycles at fixed strain or stress, or from constrained aging [16, 17]. However, these special SMAs require microstructural/metallurgical optimization to achieve sufficient stability of the effect with respect to the applications [18]. They are rarely used in actuators [10], and are not considered 
in the present study. It is worth noting that the $\mathrm{A} \leftrightarrow \mathrm{M}$ transformation is hysteretic, leading to hysteresis in the response of the material as a function of the temperature and stress history. Note also that the Joule effect is fast to employ for heating, thanks to the metallic nature of SMAs [19, 20], whereas efficient cooling generally requires sophisticated devices [21-22]. Nickel-titanium-based SMAs are the most commonly used in industrial applications, thanks to their stability, practicability, and biocompatibility [23]. They have opened wide applications and opportunities in different fields such as aeronautics [23], automotive [23], machines [24], textiles [25, 26], medical rehabilitation [27], and robotics.

In robotics, many studies deal with the behavior of SMA actuators and the influence on the behavior of mechanisms in which they are integrated [28-33]. The use of SMA requires usually the agency of at least one SMA element in an antagonism with a springback component [34-36] or another SMA component [37-41]. Actuators based on antagonistic systems with more than two components allowing several degrees of freedom (DOFs) are still rare in the literature. They may integrate three SMA elements [42, 43], four [44], or six [43, 45]. We will call them "multi-"antagonistic systems. Actuated movements and open or sensor-based control have been studied; however, to the authors' knowledge, no work has yet detailed the hysteretic aspect of multi-SMA activation.

In this article, we aim to analyze the hysteretic properties of a six-wire prestressed planar mechanism with ternary symmetry. This architecture is chosen to have redundant actuation for three independent DOFs. The two-way memory effect is used to create multidirectional actuation thanks to the antagonistic arrangement of the six SMA wires. Ternary symmetry is chosen to ease the application of initial prestressing. Each SMA wire can be thermally activated individually (heating and return to ambient temperature), one or more at a time. The hysteretic effects that are specific to this type of multi-antagonistic SMA actuation have not 
been studied in the literature from a SMA material model, to the best of the authors' knowledge. The interest in using multi-antagonistic SMA systems was demonstrated for instance in Refs [42-46]. However, no SMA material model has been employed to analyze complex hysteretic effects in the case of more than two SMA components. The present paper proposes therefore to highlight important points of the hysterical effects associated with a sixwire mechanism by using Auricchio's model [47] for the memory effect. The study was carried out via finite element (FE) calculation software with the purpose of identifying and illustrating the specific actuation characteristics of a mechanism, which may be generalized in the future to the design of multi-antagonistic SMA systems and their control modes.

The paper is organized as follows: Section 2 presents the mechanism under study; Section 3 is dedicated to the analysis of important design parameters, the possibility of locking a configuration without energy input, as well as the multi-antagonistic hysteretic behavior, highlighting its restrictive and attractive effects on the workspace; finally, Section 4 illustrates and discusses the capability of the mobile platform to reach a given position. The following notation is used for the symbols throughout the paper: italic letters are scalars and bold letters are vectors in space.

\section{Presentation of the multi-antagonistic actuation system}

\subsection{Topology of the mechanism}

Figure 1-a illustrates the general concept of the mechanism: a mobile platform is connected to several SMA wires whose thermal activation enables movement. Assuming a low bending 
stiffness of the wires (small diameter-to-length ratio), it can be considered that their connections with the base and the platform are of ball-joint type whatever the construction solution employed. In a general case, the platform could be compliant. In this case, its geometry plays a role in the kinematics of the mechanism, and anchoring the platform to the base could be allowed. In the present study, we focused on a simpler case, illustrated in Figure 1-b: the system is composed of a rigid platform with six SMA wires in the (x, y) plane and features a ternary rotational symmetry. Taking into account platform compliance is a prospect that will be considered in another study; see the conclusion section. The justification of the topology chosen here is discussed in Section 2.3, after the presentation of the mechanism's main features.

\section{$\underline{\text { Insert here Figure } 1}$}

All the wires have the same length $L$ and diameter $d$. They are placed symmetrically along the three-fold rotation axis $\mathbf{z}$. The three pairs of wires (1-2), (3-4) and (5-6) form the same angle, denoted $\alpha$ in the following. Each pair shares the same connection point with the platform. As the latter is considered as non-deformable, its geometry is simply defined by parameter $a$, corresponding to the distance between the effector point E, the center of the platform, and the connection points with the wires (Figure 1-b). Analysis in the following focuses on the rotation of the platform and on the in-plane translation of point $\mathrm{E}$, consecutive to the heating of the SMA wires. Out-of-plane deformations (due to gravity for instance) are not considered. Three geometric parameters were fixed throughout the study: $d=1 \mathrm{~mm}, L=100 \mathrm{~mm}$ and $a=$ $20 \mathrm{~mm}$ (see Table 1), whereas different values were tested for angle $\alpha$.

\section{$\underline{\text { Insert here Table } 1}$}




\subsection{Behavior of the SMA wires}

This section provides some background information about SMA wires for a better understanding of the paper. The reader can refer to Ref. [15] for further information about SMAs. Figure 2-a shows the simplified state diagram of a SMA wire in tension $[12,35]$. Material properties in this study are taken from previous experimental work (Ref. [48]) on a Ni50.8-Ti49.2 (at.\%) SMA wire $1 \mathrm{~mm}$ in diameter. The four transformation temperatures at zero stress, namely Martensite-start $\left(M_{S}\right)$, Martensite-finish $\left(M_{f}\right)$, Austenite-start $\left(A_{s}\right)$ and Austenite-finish $\left(A_{f}\right)$, were defined as $-7^{\circ} \mathrm{C},-25^{\circ} \mathrm{C}, 24^{\circ} \mathrm{C}$ and $36^{\circ} \mathrm{C}$ respectively; see Table 1 . Classically, $\mathrm{A} \rightarrow \mathrm{M}$ and $\mathrm{M} \rightarrow \mathrm{A}$ transformations do not occur at the same temperatures $\left(M_{S} \neq\right.$ $A_{f}$ and $M_{f} \neq A_{s}$ ), which leads to a so-called thermal hysteresis. It can be noted that, nongenerically, $M_{s}<A_{s}$. The ambient temperature $T_{0}$ was set to $15^{\circ} \mathrm{C}$, so that $M_{s}<T_{0}<A_{s}$. This inequality is a key point of the system's operation, as will be explained in Section 3.3. The activation temperature $T_{1}$ was set to $100^{\circ} \mathrm{C}$. Experimentally, this value can easily be reached by the Joule effect [19]. To "initialize" the SMA wires in the austenitic state, they must first be heated above $A_{f}$ at zero stress (Step 0 in Figure 2-a). The austenitic state is preserved when cooling to ambient temperature (Step 1) as $M_{S}<T_{0}$. The six wires are then prestressed simultaneously in an equivalent way on the mechanical system (Step 2), leading to their partial transformation into martensite without movement of the platform, thanks to the symmetry of the mechanism. Figure 2-b shows the corresponding stress-strain curve of the SMA wire. Five points can be highlighted from this graph.

- During monotonic loading, the $\mathrm{A} \rightarrow \mathrm{M}$ transformation occurs progressively along a socalled stress plateau. The non-linear stress-strain curve is thus defined by the elasticity line of pure austenite (100\% A), then the stress plateau, and finally the elasticity line of pure martensite $(100 \% \mathrm{M})$. 
- Let us designate $\varepsilon_{\text {pre }}$ the pre-strain level at Step 2. It is worth noting that, starting from Step 2, an increase or decrease in stress will result in different behaviors: see blue arrows A and B. An increase in stress will lead to a continuation of the transformation into martensite, while a decrease in stress will result in an "elastic" response. History effects and mechanical hysteresis are features of SMAs.

- The Young's modulus of austenite $E_{A}$ and martensite $E_{M}$ are different (see values in Table 1). During the $A \rightarrow M$ transformation, a mixture law is classically employed to calculate the Young's modulus of the austenite-martensite "composite".

- The higher the temperature is, the greater the load level is required to activate the $\mathrm{A} \rightarrow \mathrm{M}$ transformation. This property is defined by parameter $\beta$ in Figure 2-a and Table 1.

- A maximum stress $\sigma_{\max }$ was considered in the study to prevent the plasticity of the wires. Figure 2-c shows the experimental stress-strain curve until rupture, which we obtained using a uniaxial testing machine at $25^{\circ} \mathrm{C}$. After the $\mathrm{A} \rightarrow \mathrm{M}$ transformation, the plastic yield stress of the stress-induced martensite was identified as $650 \mathrm{MPa}$. The strain recoverability of NiTi SMAs was recently discussed in Ref. [49], showing that the plastic yielding of martensite appears at nearly the same stress at any test temperature. The same property was identified for austenite, but at a stress level a little higher than that of martensite [49]. In the present study, austenite measurement would have required mechanical loading at high temperature, which was not possible due to practical constraints. As the plastic yield stress of austenite is a priori a little higher than that of martensite [49], the value $\sigma_{\max }=650 \mathrm{MPa}$ was employed in the present study whatever the material's phase, which is conservative.

\section{$\underline{\text { Insert here Figure } 2}$}


From Step 3, a heating sequence is applied to the SMA wires, which may involve any wire. Note that the actuation times in a real physical system are expected to be long, see Section "Heating and cooling methods" of Ref. [10] for orders of magnitude of actuation times with respect to wire diameter and current intensity. The heating of a wire is accompanied by a partial or total disappearance of its martensitic phase (reverse transformation $M \rightarrow A$ ). In the absence of the other wires, a heated wire would return to its initial length (one-way memory effect). However, here, the six wires interact mechanically with each other. This "multiantagonistic" operation is a key point of the system, which is analyzed in Section 3.

In practice, a FE model was developed under Ansys V19 software [50]. Auricchio's model [47] was employed for SMA behavior, using BEAM188 elements and the MEFF option for the shape-memory effect. Since rotations were allowed at both ends of all the SMA wires (no bending in the wires), the model results do not depend on the number of finite elements used to mesh each wire. Ten elements were used in practice for the present simulations. The mobile platform was considered to be made of steel (Young's modulus of $200 \mathrm{GPa}$ ) with a cross-section of $150 \mathrm{~mm}^{2}$ for each of its three branches (see Figure 1-b), which makes it effectively rigid compared to the SMA wires. It was meshed using thirty finite elements. Prestrain, at Step 2, was applied by moving simultaneously the connection points of the six wires with the base, along their respective directions. Displacements were imposed at points $\mathrm{A}_{i}, i=1,2, \ldots, 6$ (see Figure 1-b): $\mathrm{A}_{1}$ and $\mathrm{A}_{2}$ were moved by $\varepsilon_{\text {pre }} \times L$ along directions $\mathrm{B}_{12} \mathrm{~A}_{1}$ and $B_{12} A_{2}$ respectively; the same was done for points $A_{3}$ and $A_{4}$ (along directions $B_{34} A_{3}$ and $\mathrm{B}_{34} \mathrm{~A}_{4}$ respectively) and points $\mathrm{A}_{5}$ and $\mathrm{A}_{6}$ (along directions $\mathrm{B}_{56} \mathrm{~A}_{5}$ and $\mathrm{B}_{56} \mathrm{~A}_{6}$ respectively). Note that calculations were made under the assumption of "large displacements", as required for SMAs. This assumption means that mechanical equilibrium is verified in the deformed state of the system at any step of the process. 


\subsection{Justification of the mechanism topology}

The topology of the mechanism was chosen by considering several points. First, geometrical symmetry was sought. It enables in particular the same pre-strain level $\varepsilon_{\text {pre }}$ at Step 2 without platform movement. Breaking the symmetry would lead to a complex definition of the initial states of the SMA wires (distinct stresses and strains at Step 2). In addition, the history of the stretching sequence of the wires from Step 1 to Step 2 would have an influence. Second, a minimum of four wires is required in theory to achieve a plane mechanism with three independent DOFs [51]. Using six SMA wires increases the global stiffness as well as the antagonistic character of the actuation. Let us recall that antagonism is required for a two-way actuation of each SMA wire (reversible movement of each wire whose basic property is oneway memory effect). Finally, the topology was in part inspired by the system developed by Jin and Zhang in Ref. [52]. In their work, the authors advantageously developed a three-arm planar compliant parallel mechanism with three linear piezoelectric actuators along constant directions. In our study, a pair of SMA wires replaces each actuator. One of the advantages of SMAs is their ability to deform elastically (and non-linearly) by several percent, making them relevant to creating larger movements. Note that although a small translation workspace (order of magnitude of $\gamma \times L= \pm 3 \mathrm{~mm}$ ) is expected compared to the dimensions of the mechanism (order of magnitude of $2 L+2 a=240 \mathrm{~mm}$ ), significant angular strokes (order of magnitude of $\gamma \times L / a \times 180 / \pi= \pm 8.5^{\circ}$ ) are a priori achievable.

\subsection{Definition of heating configurations and platform position}


For the sake of simplicity, analysis was performed by considering two thermal states per wire: either ambient temperature $T_{0}=15^{\circ} \mathrm{C}$ or activation temperature $T_{1}=100^{\circ} \mathrm{C}$. Intermediate temperatures were not considered. This point will be developed in a later study. Figure 3 shows the 64 heating configurations of the six SMA wires. A number is associated with each configuration, as well as a six-digit binary number for which " 0 " and " 1 " correspond to $T_{0}$ and $T_{1}$ respectively. For instance, the case for which all the wires are at ambient temperature corresponds to Configuration \#1 or [000000]. The case for which all the wires are at the activation temperature corresponds to Configuration \#64 or [111111]. As indicated above, the thermal activation sequence is defined from Step 3 by a series of heating configurations. The output data is a sequence of platform positions. Figure 4-a illustrates the rigid body movement of the platform. Three quantities are recorded at each step of the thermal activation sequence: the displacements $u_{x}$ and $u_{y}$ of point $\mathrm{E}$ and the rotation angle $\theta_{z}$ of the platform. Throughout the study, these quantities are defined from the initial position at Step 2. Figure 4-b shows an example in real scale of the platform position obtained for a Step 3 corresponding to Configuration \#24 or [000111]. From Figure 3, a classification of "identical" heating configurations at Step 3 can be done from rotation symmetry considerations: $\{\# 1\},\{\# 2-7\}$, $\{\# 8-10\},\{\# 11-13\},\{\# 14-16\},\{\# 17-22\},\{\# 23-28\},\{\# 29-34\},\{\# 35-40\},\{\# 41, \# 42\}$, $\{\# 43-45\},\{\# 46-51\},\{\# 52-54\},\{\# 55-57\},\{\# 58-63\},\{\# 64\}$. Each of these sets contains heating configurations leading by construction to the same magnitudes of rotation and translation at Step 3.

\section{$\underline{\text { Insert here Figure } 3}$}

\section{$\underline{\text { Insert here Figure } 4}$}

Before starting the analysis of the mechanism, the following point should be noted. The heating of a SMA wire from $T_{0}$ to $T_{1}$ tends to increase its stress level due to the other SMA 
wires (multi-antagonism). Thus, although $T_{1}>A_{f}$, heating a SMA wire to $T_{1}$ does not necessarily guarantee its complete return to the austenitic state. Indeed, any increase in stress is accompanied by a shift in the thermal range of the phase transformation: see angle $\beta$ in Figure 2-a.

\section{Analysis of the mechanism}

The multi-antagonistic and hysteretic behavior of the mechanism is now presented by progressively analyzing specific points.

- Section 3.1 presents the discrete workspace obtained at Step 3;

- Section 3.2 deals with limiting stress to avoid plasticity;

- Section 3.3 describes an advantageous property of the mechanism when stopping thermal activation;

- Section 3.4 deals with the specific cases of cyclic rotation and translation;

- Section 3.5 evidences an "attraction" effect, which is useful to reach new platform positions after Step 3.

Angle $\alpha$ and prestrain $\varepsilon_{\text {pre }}$ were set at $90^{\circ}$ and $3 \%$ respectively, except in Section 3.4 for which the influence of these two parameters is discussed.

\subsection{Discrete workspace obtained in Step 3}

Figure 5-a shows the different movements of the mobile platform obtained when applying the 64 heating confirmations at Step 3, for $\alpha=90^{\circ}$ and $\varepsilon_{\text {pre }}=3 \%$. Each movement is defined in the graph by three coordinates $\left(u_{x}, u_{y}, \theta_{z}\right)$ whose definition was given in the previous 
section. For an easier visualization, Figure 5-b provides the projection of the points in the $\left(u_{x}, u_{y}\right)$ plane, highlighting the translation only, while Figure 5-c provides the values $\theta_{z}$ for platform rotation only. Numbers in these figures refer to the heating configurations defined in Figure 3. Several points can be noted from Figure 5:

- Red crosses correspond to situations for which negative stresses are calculated in at least one SMA wire. Such cases are considered as not permissible, in order to avoid buckling situations. Even if buckling does not systematically prevent the mechanism from operating, it is difficult to correctly predict the bending behavior of SMA wires which will then have to work in tension again.

- As expected, Configurations \#1 (no wire heated) and \#64 (all the wires heated) led to no movement. The latter case is due to the symmetry of both the geometry and the actuation. Heating configurations \#41 and \#42 led to pure rotation, i.e. $u_{x}=0$ and $u_{y}$ $=0$. This observation is logical because of the three-fold symmetry of the heated wires (see Figure 3). The maximum rotation magnitude $\left|\theta_{z}\right|$ was obtained for these two heating configurations: almost $10.3^{\circ}$ (see Figure 5-c). Heating configurations \#8-16, $\# 43-45$ and \#52-57 led to pure translation, i.e. $\theta_{z}=0$. This property is inherited from a two-fold symmetry of the heated wires in these cases. The maximum translation magnitude $\sqrt{u_{x}^{2}+u_{y}^{2}}$ reached is almost $3.7 \mathrm{~mm}$, for Configurations \#23-28 and \#55-57. Table 2 sums up the sets of identical heating configurations in terms of translation magnitude, as well as in terms of rotation by taking into account the sign of the rotation angle $\theta_{z}$ (null, strictly positive or strictly negative). For example, positive and negative rotations with same magnitude are obtained for $\{\# 3, \# 5, \# 7\}^{+}$and $\{\# 2$, $\# 4, \# 6\}^{-}$respectively.

\section{Insert here Table 2}


The dot cloud of the discrete workspace in Figure 5-b exhibits a three-fold symmetry, as a consequence of the symmetry of the mechanism. Other locations can be achieved in $\left(u_{x}, u_{y}, \theta_{z}\right)$ space with adequate thermal activation sequences, as shown later in this paper. Before that, the next section is dedicated to a remark about limitations in terms of the stress level in the SMA wires.

\section{$\underline{\text { Insert here Figure } 5}$}

\subsection{Remark about maximum stress in the wires}

Calculations were performed using a FE model that does not take plasticity into account. This potentially leads to stress values higher than the maximum allowed $\left(\sigma_{\max }=650 \mathrm{MPa}\right.$; see Section 2.2). Table 3 gives an example of results obtained by applying successively Configurations \#21 and \#59 at Steps 3 and 4 respectively (again for $\alpha=90^{\circ}$ and $\varepsilon_{\text {pre }}=3 \%$ ). It can be observed that stress in wire 3 at Step 4 exceeds $\sigma_{\max }$, meaning that the thermal activation sequence is not valid. Attention was paid in the data analysis to cancelling any thermal activation sequence for which the stress in at least one wire at any step exceeds the plastic yield stress of the SMA.

\section{$\underline{\text { Insert Table } 3}$}

From a general point of view, excessive stresses can be avoided by limiting either the number of activated wires or the activation temperature. Figure 6 illustrates for instance the effect of overheating the SMA wires (above $T_{1}=100^{\circ} \mathrm{C}$ ): the plot is similar to that in Figure 5 -a but 
the activation temperature was increased until a full return to the austenitic state of the heated wires was achieved. Red crosses correspond to non-valid configurations, for which stresses are either negative or exceed the plastic yield stress of the SMA. It can be seen that many heating configurations are not valid. In the following, the activation temperature was maintained at $T_{1}=100^{\circ} \mathrm{C}$, which is actually a good compromise to limit the number of nonvalid configurations. In the rest of the paper, non-valid configurations are no longer indicated in the graphs and are removed from the analysis.

\section{$\underline{\text { Insert here Figure } 6}$}

\subsection{Advantageous property of the system}

An interesting feature of the system can be highlighted. Indeed, Figure 7 shows that platform position is partially preserved when thermal activation is halted. This was illustrated by applying a return to ambient temperature (Configuration \#1 or [000000]) at Step 4 after any Configuration \#j applied at Step 3: see Figure 7-a. Figure 7-b shows the coordinates $\left(u_{x}, u_{y}, \theta_{z}\right)$ obtained at Steps 3 and 4, while Figure 7-c provides the projection in the plane $\left(u_{x}, u_{y}\right)$. It can be observed that the platform positions at Steps 3 and 4 do not coincide. Moreover, the platform at Step 4 (square blue symbols) is not returned to the initial position $\left(u_{x}=0, u_{y}=0, \theta_{z}=0\right)$, obviously except for $j=1$ and $j=64$, for which the platform was already in its initial position at Step 3. It can be noted that only a small part of the movement was "lost"; the square blue symbols (Step 4) are close to the black dots (Step 3). This property is interesting from an applicative point of view: it is possible to stop the activation of the system while maintaining an activation state. This feature is a consequence of the choice of the Martensite-start and Austenite-start temperatures such that $M_{S}<T_{0}<A_{S}$ (see Section 
2.2). This inequality means that cooling to $T_{0}$ does not imply systematically an $A \rightarrow M$ transformation because $M_{S}<T_{0}$ (transformation may however occur due to the stress which shifts the transformation domain, as explained in Section 2.4). The wire remains thus completely or nearly completely austenitic once it is returned to ambient temperature. In the following, any heating step is followed by a return to ambient temperature of the activated wires. This choice was made to obtain a series of "bi-stable" states ("multi-stable" mechanism).

\section{$\underline{\text { Insert here Figure } 7}$}

As indicated above, a complex interaction exists between the six wires. This interaction involves several constraints:

(i) elasticity governed by Young's modulus;

(ii) phase transformation governed by the state diagram in Figure 2-a and the thermomechanical history of the wires;

(iii) static equilibrium of the platform, in deformed configuration as indicated in Section 2.2;

(iv) geometrical compatibility of the lengths of the wires (which defines the position of the platform).

The advantageous property of the system presented in this section is an illustration of this complex interaction. In particular, constraint (ii) is at the origin of the system's hysteretic response, whose consequences will be explored in the following sections. 


\subsection{Specific cases of cyclic rotation and translation}

Before applying thermal activation sequences involving various heating configurations, this section is dedicated to the cyclic use of two configurations aiming at creating a cyclic movement of the platform. In particular, the specific cases of pure rotation and pure translation are here discussed.

First, Figure 8-a describes the thermal activation sequence considered to obtain a cyclic rotation, by alternating Configurations \#41 and \#42 with intermediate returns to ambient temperature. Variations in rotation angle $\theta_{z}$ for $\alpha=90^{\circ}$ and $\varepsilon_{\text {pre }}=3 \%$ can be visualized in Figure 8 -b. Negative $\left(-10.3^{\circ}\right)$ and positive $\left(10.3^{\circ}\right)$ rotations are obtained for Configurations $\# 41$ and \#42 respectively, leading to a signal amplitude $\left(\Delta \theta_{z}\right)_{\max }=20.6^{\circ}$. A partial preservation of the rotation angle when stopping the thermal activation is observed at Steps 4, $6,8,10$, etc., as expected from the discussion in the previous section. The rotation amplitude, taking into account these intermediate returns to ambient temperature, is equal to $\left(\Delta \theta_{z}\right)_{\min }=$ $17.8^{\circ}$. Further analysis can be carried out by extracting the stress and strain values after each step: see Figure 8-c. Several comments can be made from these graphs.

- Due to the three-fold symmetry of the heating configurations \#41 and \#42, variations were the same in wires 1, 3 and 5 (left graph) and in wires 2, 4 and 6 (right graph).

- From Step 2 to Step 3, strain decreased in wires 1, 3, 5 (memory effect) and increased in wires 2, 4, 6 by compensation. Moreover, as noted in Section 2 (blue arrow A in Figure 2-b), the continuation of the transformation into martensite of wires 2, 4, 6 is accompanied by a stress increase. Note also that, at Step 3, the stress in wires 2, 4, 6 (about $312 \mathrm{MPa}$ ) is different from the stress in wires 1, 3, 5 (about $454 \mathrm{MPa}$ ). Indeed, 
constraint (iii) in Section 3.3 regarding the static equilibrium of the platform can be rewritten as follows:

(iii-1) the three force vectors created by each pair of wires $\left(\mathbf{F}_{1}+\mathbf{F}_{2}, \mathbf{F}_{3}+\mathbf{F}_{4}\right.$ and $\mathbf{F}_{5}+\mathbf{F}_{6}$ ) must intersect at the same point;

(iii-2) the sum of the six force vectors $\mathbf{F}_{1}+\mathbf{F}_{2}+\mathbf{F}_{3}+\mathbf{F}_{4}+\mathbf{F}_{5}+\mathbf{F}_{6}$ must be equal to zero.

No equality between magnitudes $F_{1}$ and $F_{2}$ (or $F_{3}$ and $F_{4}$, or $F_{5}$ and $F_{6}$ ) is required for the equilibrium of the system.

- From Step 3 to Step 4, the strain slightly decreases in wires 2, 4, 6, and slightly increases in wires $1,3,5$ by compensation. The decrease in wires $2,4,6$ is due to "elastic" unloading, which was indicated by the blue arrow B in Figure 2-b.

- The other subsequent steps can be explained from the same principles.

\section{$\underline{\text { Insert here Figure } 8}$}

For the same thermal activation sequence as in Figure 8-a (cyclic rotation by alternating heating configuration \#41 and \#42 with intermediate returns to ambient temperature), Figure 9-a shows the influence of angle $\alpha$ on the rotation amplitudes $\left(\Delta \theta_{z}\right)_{\max }$ and $\left(\Delta \theta_{z}\right)_{\min }$, see Figure 8-b for the definition of these two quantities. Prestrain $\varepsilon_{\text {pre }}$ was again fixed to $3 \%$ in these calculations. As expected, when the angle is closed $\left(\alpha=0^{\circ}\right)$, no rotation is obtained. As also expected, when the wires are aligned $\left(\alpha=180^{\circ}\right)$, large rotations are obtained. The maximum values for $\left(\Delta \theta_{z}\right)_{\max }$ and $\left(\Delta \theta_{z}\right)_{\min }$ are obtained here for $\alpha=90^{\circ}$. However, larger rotation amplitudes can be obtained by changing the pre-strain level $\varepsilon_{\text {pre. }}$ Figure 9-b shows the influence of $\varepsilon_{\text {pre }}$ maintaining $\alpha$ at $90^{\circ}$. Following comments can be made from this graph. 
- As expected, no rotation is obtained if the SMA wires were not pre-strained at Step 2 $\left(\varepsilon_{\text {pre }}=0 \%\right)$. Increasing the pre-strain level tends first to increase the rotation amplitudes. This observation is logical, as the memory effect in the heated wires depends on this parameter (in the absence of stress, the heated wires would return to their initial length, i.e., the strain change from Step 3 to Step 4 would be equal to $\left.-\varepsilon_{\text {pre }}\right)$.

- Increasing the pre-strain level excessively tends to decrease the rotation amplitudes. Indeed, let us consider for instance the case for which all wires are completely martensitic $(100 \% \mathrm{M})$ at Step 2: when wires 1, 3, 5 are heated at Step 3, their memory effect is countered by the high stiffness $E_{M}$ of the martensitic wires 2, 4, 6 (see blue arrow $\mathrm{C}$ in Figure 2-b). The more the pre-strain level approaches the end of the stress plateau, the faster a high stiffness value is reached for wires $2,4,6$ when wires $1,3,5$ are heated.

- The optimal value of $\varepsilon_{\text {pre }}$ to maximize the rotation amplitude corresponds to the middle of the stress plateau of the stress-strain curve. Its value can be expressed as follows

$$
\left(\varepsilon_{\text {pre }}\right)_{\text {opt }}=\frac{\gamma}{2}+\frac{\beta \times\left(T_{0}-M_{S}\right)}{E_{A}}
$$

where $\gamma$ is the total phase deformation strain (see Table 1 and Figure 2-b). In this equation, the last term is the strain at the onset of the $A \rightarrow M$ transformation. Using data from Table 1, Equation (1) gives $\left(\varepsilon_{\text {pre }}\right)_{\text {opt }}=3.3 \%$, leading then to $\left[\left(\Delta \theta_{z}\right)_{\max }\right]_{\mathrm{opt}}$ $=21.1^{\circ}$ and $\left[\left(\Delta \theta_{z}\right)_{\min }\right]_{\mathrm{opt}}=18.1^{\circ}$.

\section{$\underline{\text { Insert here Figure } 9}$}


The same approach was developed for the case of a cyclic translation, by alternating Configurations \#8 and \#13 with intermediate returns to ambient temperature: see Figure 10-a. These two heating configurations lead to translations along the $\mathbf{y}$-axis only, due to the vertical symmetry of these heated wires. Figure 10-b shows the influence of angle $\alpha$ on the translation amplitudes $\left(\Delta u_{y}\right)_{\max }$ and $\left(\Delta u_{y}\right)_{\min }$, keeping $\varepsilon_{\text {pre }}$ at $3 \%$. The gray-shaded rectangles in the graph correspond to non-valid configurations, i.e. situations for which stresses are negative or exceed the plastic yield stress of the SMA. It can be noted that there are large ranges of values for angle $\alpha$ which are not valid, and from $131^{\circ}$ to $180^{\circ}$, only translations lower than $1 \mathrm{~mm}$ are possible. As expected when the heated wires are aligned and parallel to the $\mathbf{x}$-axis $\left(\alpha=180^{\circ}\right)$, no translation is obtained. From $50^{\circ}$ to $70^{\circ}$, greater translations are possible. Values are nearly constant: $\left(\Delta u_{y}\right)_{\max }=5.8 \mathrm{~mm}$ and $\left(\Delta u_{y}\right)_{\min }=5.2 \mathrm{~mm}$. Figure 10-c shows the influence of $\varepsilon_{\text {pre }}$ for $\alpha=60^{\circ}$. Similarly to the rotation case above, increasing the pre-strain level excessively (here $\varepsilon_{\text {pre }}>6.8 \%$ ) tends to decrease movement amplitudes. Furthermore, translation amplitudes increase with $\varepsilon_{\text {pre }}$ in the range [0\%; 4.0\%]. Optimal values are $\left[\left(\Delta u_{y}\right)_{\max }\right]_{\mathrm{opt}}=7.8 \mathrm{~mm}$ and $\left[\left(\Delta u_{y}\right)_{\mathrm{min}}\right]_{\mathrm{opt}}=6.8 \mathrm{~mm}$ at $\varepsilon_{\mathrm{pre}}=4.0 \%$. It can be noted that this latter value actually corresponds to the boundary of a non-valid domain. This means that, in an experimental context, attention should be paid to avoid falling into an undesired situation, by applying for instance a pre-strain slightly lower than $4.0 \%$.

\section{$\underline{\text { Insert here Figure } 10}$}

It can be noted that, as expected, the optimal parameters for translation and for rotation are distinct. Seeking both a large rotation and a large translation requires a compromise. 


\subsection{Evidence of an attraction effect}

An "attraction effect" can be evidenced by analyzing the impact of a given heating configuration at Step 3 on the subsequent steps. Let us consider for instance Configuration \#24 at Step 3, followed by a return to ambient temperature at Step 4, and finishing by Configuration \#k at Step 5 with $k \in\{1, \ldots 64\}$ : see Figure 11-a. Again for $\alpha=90^{\circ}$ and $\varepsilon_{\text {pre }}=$ $3 \%$, Figure 11-b shows the coordinates $\left(u_{x}, u_{y}, \theta_{z}\right)$ obtained at Steps 3 and 5 , while Figure 11-c provides the projection in the plane $\left(u_{x}, u_{y}\right)$. It can be seen in these graphs that many points at Step 5 are close to the point at Step 3. More precisely, a point cloud is located in a neighborhood of Step 3 (see close-up in Figure 12), whereas other points remain far away. This property opens the possibility of reaching various new platform positions around any given position, while retaining the ability to "jump" far away in the workspace at any time. In the example developed in Figure 11, from the heating configuration \#24 at Step 3, it is possible to reach a close position for the platform at Step 5 (red square symbols inside the dashed rectangle in Figure 11-c), but it is also possible to reach a distant position (red square symbols outside the dashed rectangle).

\section{Insert here Figure 11}

\section{$\underline{\text { Insert here Figure } 12}$}

It is interesting to note that the platform positions at Step 5 that are close to the position at Step 3 exhibit strongly distinct global stiffnesses: see Table 4. Calculations were made at Step 5 for Configurations \#5, \#6, \#10, \#13 and \#17, corresponding to the closest five platform positions to Step 3 (\#24); see Figure 12. Stiffness at Step 3 was also calculated for 
comparison purposes. Components $K_{x x}$ and $K_{y y}$ of the stiffness matrix were obtained by applying a force of $100 \mathrm{~N}$ along the $\mathbf{x}$-axis and $\mathbf{y}$-axis, respectively, at point $\mathrm{E}$ of the platform. Component $K_{\theta \theta}$ was obtained by applying a torque of 100 N.mm along the z-axis. Note that each component was calculated from a specific simulation because of the non-additivity of the effects of each force component; see Refs. $[12,30]$ for details about the non-linearity and anisotropy of stiffness variability when SMA components are employed in a mechanism. Variability in the stiffness values is evidenced from Table 4. It can be explained by differences in the proportion of austenite and martensite of the SMA wires. Globally, the higher the proportion of austenite in the system, the higher the global stiffness, because $E_{A}>$ $E_{M}$ (see Table 1). However, let us recall that the transformation to austenite of a given wire by heating tends to deform antagonistic wires, which therefore transform to martensite... We note that the value $K_{y y}$ at Step $3\left(0.91 \mathrm{kN} \cdot \mathrm{mm}^{-1}\right)$ is lower than all the values calculated at Steps 5 ( $\max 1.22 \mathrm{kN} \cdot \mathrm{mm}^{-1}$ for Configuration \#6). This can be explained by the fact that all the heated wires in Configurations \#5, \#6, \#10,\#13 and \#17 (Steps 5) had already been activated at Step 3. Wider variabilities are observed for the $K_{x x}\left(\min 0.42 \mathrm{kN} . \mathrm{mm}^{-1}\right.$, max $1.04 \mathrm{kN} . \mathrm{mm}^{-}$ $\left.{ }^{1}\right)$ and $K_{\theta \theta}\left(\min 258 \mathrm{kN} \cdot \mathrm{mm} \cdot \mathrm{rad}^{-1}\right.$, $\left.\max 480 \mathrm{kN} \cdot \mathrm{mm}^{\mathrm{rad}}{ }^{-1}\right)$ components. This variability opens prospects for the optimization of variable global stiffness.

\section{$\underline{\text { Insert here Table } 4}$}




\section{Final remark concerning the possibility of reaching a target position in the workspace}

Finally, before concluding this paper, this section shows that it is possible to reach a target position for the platform using a sequence of heating configurations. It is important to note that the objective here is not to develop a direct or inverse model of the studied mechanism. The objective is simply to show that it is possible reach a given platform position using an empirical approach. Starting from Step 2, the following target was arbitrary defined: $\left(u_{x}, u_{y}\right.$, $\left.\theta_{z}\right)=\left(-2.80 \mathrm{~mm}, 1.95 \mathrm{~mm}, 1.2^{\circ}\right)$ with a precision of $0.1 \mathrm{~mm}$ and $0.1^{\circ}$ for the translation and the rotation respectively. As a constraint, each heating configuration must be followed by a return to ambient temperature $T_{0}$ (Configuration \#1), creating thus a series of "bi-stable" states. In particular, the thermal activation sequence must finish with Configuration \#1. Figure 13-a shows the different steps obtained in the $\left(u_{x}, u_{y}\right)$ plane; Figure 13-b shows the variation in angle $\theta_{z}$. The target is reached here in four heating configurations (and four returns to ambient temperature). Numerous other thermal activation sequences can lead to the same target. However, the following simple principle can be expressed a priori: it is possible to reach a target by applying a sequence of heating configurations in the "neighborhood" of each other. For instance Configuration \#16 is in the vicinity of Configuration \#24 (see Figure 12); then Configuration \#6 is in the vicinity of Configuration \#16; etc., until the target is attained. This opens perspectives for the control of the mechanism.

$\underline{\text { Insert here Figure } 13}$ 


\section{Conclusion}

A mechanism with six SMA wires (allowed to be thermally activated individually) was analyzed using a FE simulation based on Auricchio's model for the memory effect of the SMA material. Its multi-antagonistic and hysteretic response was illustrated using various thermal activation sequences. Important points were discussed, such as:

(1) the possibility of locking a configuration without energy input;

(2) the avoidance of plasticity of the SMA wires;

(3) the attraction effect of any heating step on the following steps;

(4) stiffness variability as a function of the applied thermal sequence.

Although point (1) is well known in the literature, the other three points are rarely addressed, although they are important for the control of multi-antagonistic SMA systems. Prior to any design, thermo-mechanical models available in the literature for SMA components should be employed for the proper simulation of new multi-antagonistic actuation systems based on these active materials, in order to correctly address all four points.

The studied mechanism featured a small translation workspace (about $7 \mathrm{~mm}$ ) but a significant angular stroke (about $20^{\circ}$ ). This makes it potentially interesting as a hollow shaft rotary actuator with additional (small) translation DOFs. Let us note that the concept can easily accommodate size reduction. Homothetic reduction of the dimensions can be implemented while retaining the same amplitude of rotation; in addition, size reduction is advantageous for improving (reducing) activation times, both for Joule heating and convection cooling. The proposed design could therefore find potential applications in micro-robotics for applications requiring long-term and stable positioning at ambient temperature (i.e. without energy input). 
Funding No funding received.

\section{Compliance with ethical standards}

Conflict of interest The authors declare that they have no conflict of interest.

\section{References}

1. Higuchi T, Suzumori K, Tadokoro S (2010) Next-generation actuators leading breakthroughs. Springer-Verlag, London, UK. http://dx.doi.org/10.1007/978-1-84882991-6

2. Rakotondrabe M (2013) Smart materials-based actuators at the micro/nano-scale. Springer-Verlag, New-York, USA. https://doi.org/10.1007/978-1-4614-6684-0

3. Asaka K, Okuzaki H (2014) Soft actuators. Springer Japan, Tokyo, Japan. https://doi.org/10.1007/978-4-431-54767-9

4. Khoo ZX, Teoh JEM, Liu Y, Chua CK, Yang SF, An J, Leong KF, Yeong WY (2015) 3D printing of smart materials: a review on recent progresses in 4D printing. Virtual Phys Prototyp 10:103-122

5. Le HM, Do TN, Phee SJ (2016) A survey on actuators-driven surgical robots. Sens Actuators -Phys 247:323-354

6. Couture T, Szewczyk J (2018) Design and experimental validation of an active catheter for endovascular navigation. J Med Devices 12:011003

7. Kheirikhah MM, Rabiee S, Edalat ME (2010) A review of shape memory alloy actuators in robotics. In: Ruiz-del-Solar J, Chown E, Plöger PG (Eds.) RoboCup 2010: Robot Soccer World Cup XIV. Lecture Notes in Computer Science, vol 6556, pp 206-217. Springer, Berlin, Heidelberg. https://doi.org/10.1007/978-3-642-20217-9_18

8. Hines L, Petersen K, Lum GZ, Sitti M (2017) Soft actuators for small-scale robotics. Adv Mater 29:1603483

9. Mohd Jani J, Leary M, Subic A (2017) Designing shape memory alloy linear actuators: a review. J Intell Mater Syst Struct 28:1699-1718

10. Yuan H, Fauroux JC, Chapelle F, Balandraud X (2017) A review of rotary actuators based on shape memory alloys. J Intell Mater Syst Struct 28:1863-1885

11. Liu C, Dong E, Xu M, et al (2018) Locomotion analysis and optimization of actinomorphic robots with soft arms actuated by shape memory alloy wires. Int J Adv Robot Syst 15:1729881418787943 
12. Mekaouche A, Chapelle F, Balandraud X (2018) A compliant mechanism with variable stiffness achieved by rotary actuators and shape-memory alloy. Meccanica 53:2555-2571

13. Karakalas AA, Machairas TT, Saravanos DA (2019) Effect of shape memory alloys partial transformation on the response of morphing structures encompassing shape memory alloy wire actuators. J Intell Mater Syst Struct 30:1682-1698

14. Xu L, Cai Z, He X (2019) A harmonic movable tooth drive system integrated with shape memory alloys. Smart Struct Syst 23:319-327

15. Otsuka K, Wayman CM (1999) Shape memory materials. Cambridge university press, Cambridge, UK

16. Chen L, Si N (2008) Influence of thermomechanical training deformations on twsme in tinicu alloy spring. J Alloy Compd 448(1): 219-222

17. Wada K, Liu Y (2008) On the mechanisms of two-way memory effect and stress-assisted two-way memory effect in NiTi shape memory alloy. J Alloy Compd 449(1): 125-128

18. Scherngell H, Kneissl A (2002) Generation, development and degradation of the intrinsic two-way shape memory effect in different alloy systems. Acta Mater 50(2):327-341

19. Debska A, Balandraud X, Destrebecq JF, et al (2017) Influence of thermal boundary effects on the process of creating recovery stresses in a SMA wire activated by Joule heating. J Mater Eng Perform 26:3336-3346

20. Prabu SM, Mithun R, Muralidharan M, et al (2019) Thermo-mechanical behavior of shape memory alloy spring actuated using novel scanning technique powered by ytterbium doped continuous fiber laser. Smart Mater Struct 28:047001

21. Cheng SS, Kim Y, Desai JP (2017) Modeling and characterization of shape memory alloy springs with water cooling strategy in a neurosurgical robot. J Intell Mater Syst Struct 28:2167-2183

22. Doroudchi A, Zakerzadeh MR, Baghani M (2018) Developing a fast response SMAactuated rotary actuator: modeling and experimental validation. Meccanica 53:305-317

23. Jani JM, Leary M, Subic A, Gibson MA (2014) A review of shape memory alloy research, applications and opportunities. Mater Des 56:1078-1113

24. Alves MTS, Steffen Jr V, Castro dos Santos M, et al (2018) Vibration control of a flexible rotor suspended by shape memory alloy wires. J Intell Mater Syst Struct 29:2309-2323

25. Persson N-K, Martinez JG, Zhong Y, et al (2018) Actuating textiles: next generation of smart textiles. Adv Mater Technol 3:1700397 
26. Kongahage D, Foroughi J (2019) Actuator materials: review on recent advances and future outlook for smart textiles. Fibers 7:21

27. Gul JZ, Yang YJ, Su KY, Choi KH (2017) Omni directional multimaterial soft cylindrical actuator and its application as a steerable catheter. Soft Robot 4:224-240

28. Koh JS, Cho KJ (2013) Omega-shaped inchworm-inspired crawling robot with largeindex-and-pitch (LIP) SMA spring actuators. IEEE ASME Trans Mechatron 18:419-429

29. Peraza-Hernandez EA, Hartl DJ, Malak RJ (2013) Design and numerical analysis of an SMA mesh-based self-folding sheet. Smart Mater Struct 22:094008

30. Mekaouche A, Chapelle F, Balandraud X (2016) Using shape memory alloys to obtain variable compliance maps of a flexible structure: concept and modeling. Meccanica 51:1287-1299

31. Benafan O, Gaydosh DJ (2017) High temperature shape memory alloy Ni50.3Ti29.7Hf20 torque tube actuators. Smart Mater Struct 26:095002

32. Micheletti A, dos Santos FA, Sittner P (2018) Superelastic tensegrities: matrix formulation and antagonistic actuation. Smart Mater Struct 27:105028

33. Gédouin P-A, Pino L, Chirani SA, et al (2019) R-phase shape memory alloy helical spring based actuators: modeling and experiments. Sens Actuators Phys 289:65-76

34. Shi ZC, Al Hajjar H, Prelle C, Liu XX, Ilou L, Lamarque F (2018) Optimization of an optically controlled bistable micro-actuator. In: IEEE ASME International Conference on Advanced Intelligent Mechatronics (AIM). IEEE, pp 1148-1153. https://doi.org/10.1109/AIM.2018.8452374

35. Yuan H, Chapelle F, Fauroux JC, Balandraud X (2018) Concept for a 3D-printed soft rotary actuator driven by a shape-memory alloy. Smart Mater Struct 27:055005

36. White TD, Hartl DJ (2019) Exploration of static equilibrium in elastically biased shape memory alloy components. In: Naguib HE (Ed.) Behavior and Mechanics of Multifunctional Materials XIII. International Society for Optics and Photonics, 109680B. https://doi.org/10.1117/12.2514343

37. Moallem M, Tabrizi VA (2008) Tracking control of an antagonistic shape memory alloy actuator pair. IEEE Trans Control Syst Technol 17:184-190

38. Sofla AYN, Elzey DM, Wadley HNG (2008) Two-way antagonistic shape actuation based on the one-way shape memory effect. J Intell Mater Syst Struct 19:1017-1027

39. Zhang K, Qiu C, Dai JS (2015) Helical kirigami-enabled centimeter-scale worm robot with shape-memory-alloy linear actuators. J Mech Robot 7:021014 
40. Kciuk M, Kuchcik W, Pilch Z, Klein W (2019) A novel SMA drive based on the Graham Clock escapement and resistance feedback. Sens Actuators Phys 285:406-413

41. Moghadam MH, Zakerzadeh MR, Ayati M (2019) Robust sliding mode position control of a fast response SMA-actuated rotary actuator using temperature and strain feedback. Sens Actuators Phys 292:158-168

42. Sreekumar M, Nagarajan T, Singaperumal M (2009) Application of trained NiTi SMA actuators in a spatial compliant mechanism: experimental investigations. Mater Des 30:3020-3029

43. Salerno M, Zhang K, Menciassi A, Dai JS (2016) A novel 4-DOF origami grasper with an SMA-actuation system for minimally invasive surgery. IEEE Trans Robot 32:484-498

44. Rodrigue H, Wang W, Bhandari B, et al (2015) SMA-based smart soft composite structure capable of multiple modes of actuation. Compos Part B Eng 82:152-158

45. White EL, Case JC, Kramer-Bottiglio R (2017) A soft parallel kinematic mechanism. Soft Robot 5:36-53

46. Mollaei M, Mascaro S (2013) Optimal control algorithm for multi-input binarysegmented SMA actuators applied to a multi-DOF robot manipulator. Proceedings of the ASME 2013 Dynamic Systems and Control Conference DSCC2013 October 21-23, 2013, Palo Alto, California, USA. https://doi.org/10.1115/DSCC2013-4094

47. Auricchio F (2001) A robust integration-algorithm for a finite-strain shape-memory-alloy superelastic model. Int J Plast 17:971-990

48. Tran H, Balandraud X, Destrebecq JF (2015) Improvement of the mechanical performances of concrete cylinders confined actively or passively by means of SMA wires. Arch Civ Mech Eng 15:292-299

49. Heller L, Sittner P, Sedlak P, Seiner H, Tyc O, Kaderavek L, Sedmak P, Vronka M (2019) Beyond the strain recoverability of martensitic transformation in NiTi. Int J Plast 116:232-264

50. Mekaouche A, Chapelle F, Balandraud X (2015) FEM-based generation of stiffness maps. IEEE Trans Robot 31:217-222

51. Merlet JP (2013) Wire-driven parallel robot: open issues. In: Padois V, Bidaud P, Khatib O (Eds.) Romansy 19-Robot Design, Dynamics and Control. CISM International Centre for Mechanical Sciences, vol 544, Springer, Vienna. DOI: 10.1007/978-3-7091-1379-0_1

52. Jin M, Zhang X (2016) A new topology optimization method for planar compliant parallel mechanisms. Mech Mach Theory 95:42-58 
Table 1. Parameters fixed for the study.

\begin{tabular}{lll}
\hline Symbol & Signification & Value \\
\hline$E_{M}$ & Young modulus of martensite & $35,000 \mathrm{MPa}$ \\
$E_{A}$ & Young modulus of austenite & $63,000 \mathrm{MPa}$ \\
$\sigma_{\max }$ & Maximum stress to prevent plasticity (elastic limit) & $650 \mathrm{MPa}$ \\
$M_{S}$ & Martensite-start temperature & $-7{ }^{\circ} \mathrm{C}$ \\
$M_{f}$ & Martensite-finish temperature & $-25{ }^{\circ} \mathrm{C}$ \\
$A_{s}$ & Austenite-start temperature & $24{ }^{\circ} \mathrm{C}$ \\
$A_{f}$ & Austenite-finish temperature & $36{ }^{\circ} \mathrm{C}$ \\
$T_{0}$ & Ambient temperature & $15{ }^{\circ} \mathrm{C}$ \\
$T_{1}$ & Activation temperature & $100{ }^{\circ} \mathrm{C}$ \\
$\gamma$ & Maximum transformation strain & $6 \%$ \\
$\beta$ & Slope of the transformation lines in the state diagram & $8 \mathrm{MPa} /{ }^{\circ} \mathrm{C}$ \\
$d$ & Diameter of the SMA wires & $1 \mathrm{~mm}$ \\
$L$ & Length of the SMA wire & $100 \mathrm{~mm}$ \\
\hline & Length of the platform bar & $20 \mathrm{~mm}$ \\
\hline
\end{tabular}


Table 2. Classification of the heating configurations applied at Step 3 leading to the same movement in terms of translation magnitude $\sqrt{u_{x}^{2}+u_{y}^{2}}$ or rotation magnitude $\left|\theta_{z}\right|$. Numbers refer to the configurations in Figure 3. Exponent " 0 " is used when the magnitude is equal to zero. Symbol "/" separates sets with the same rotation amplitude $\left|\theta_{z}\right|$ but opposite rotation sign. Exponents "+" and "-" refer to the sign of the rotation.

\begin{tabular}{ll}
\hline Property & Set of similar heating configurations at Step 3 \\
\hline Same translation magnitude & $\{\# 1, \# 41, \# 42, \# 64\}^{0},\{\# 14-16\},\{\# 52-54\},\{\# 35-40\},\{\# 2-7\}$, \\
& $\{\# 58-63\},\{\# 46-51\},\{\# 17-22\},\{\# 29-34\},\{\# 43-45\},\{\# 11-13\}$, \\
& $\{\# 8-10\},\{\# 55-57\},\{\# 23-28\}$ \\
& $\{\# 1, \# 8-16, \# 43-45, \# 52-57, \# 64\}^{0}$, \\
Same rotation magnitude & $\{\# 30, \# 31, \# 34\}^{+} /\{\# 29, \# 32, \# 33\}^{-}$, \\
& $\{\# 24, \# 25, \# 28\}^{+} /\{\# 23, \# 26, \# 27\}^{-}$, \\
& $\{\# 35, \# 37, \# 40, \# 58, \# 60, \# 63\}^{+} /\{\# 36, \# 38, \# 39, \# 59, \# 61, \# 62\}^{-}$, \\
& $\{\# 3, \# 5, \# 7\}^{+} /\{\# 2, \# 4, \# 6\}^{-}$, \\
& $\{\# 47, \# 49, \# 51\}^{+} /\{\# 46, \# 48, \# 50\}^{-}$, \\
& $\{\# 17, \# 18, \# 21\}^{+} /\{\# 18, \# 20, \# 22\}^{-}$, \\
& $\{\# 42\}^{+} /\{\# 41\}^{-}$
\end{tabular}


Table 3. Example of a (non-valid) thermal activation sequence leading to plasticity. Configurations \#21 and \#59 are successively applied at Steps 3 and 4 respectively (for $\alpha=$ $90^{\circ}$ and $\varepsilon_{\text {pre }}=3 \%$ ). The stress value exceeding the plastic yield stress of the SMA is underlined.

\begin{tabular}{|c|c|c|c|c|c|c|c|c|c|c|}
\hline \multirow[t]{2}{*}{ Step } & \multirow[t]{2}{*}{ Config. } & \multicolumn{4}{|c|}{ Positions of the platform } & \multicolumn{5}{|c|}{ Stresses in the six wires (in MPa) } \\
\hline & & $u_{x}(\mathrm{~mm})$ & $u_{y}(\mathrm{~mm})$ & $\theta_{z}\left(^{\circ}\right)$ & 1 & 2 & 3 & 4 & 5 & 6 \\
\hline Step 2 & $\# 1$ & \multicolumn{3}{|c|}{0 for the three quantities } & \multicolumn{6}{|c|}{255 in the six wires } \\
\hline Step 3 & \#21 & -0.52 & -1.93 & 6.2 & 203 & 357 & 289 & 267 & 324 & 386 \\
\hline Step 4 & \#59 & -3.00 & 1.02 & 2.4 & 472 & 326 & 709 & 521 & 430 & 622 \\
\hline
\end{tabular}


Table 4. Evidence of strong variability of stiffness in a given zone of the workspace. Steps 3 and 5 refer to the thermal activation sequence in Figure 11-a. Components $K_{x x}, K_{y y}$ and $K_{\theta \theta}$ of the stiffness matrix were obtained by applying a force of $100 \mathrm{~N}$ and a torque of $100 \mathrm{kN} . \mathrm{mm}$ at point E.

\begin{tabular}{cccc}
\hline $\begin{array}{c}\text { Heating configuration } \\
\text { at Step 5 }\end{array}$ & $K_{x x}$ & $K_{y y}$ & $K_{\theta \theta}$ \\
\hline \#5 & 0.42 & 1.00 & 372 \\
$\# 6$ & 0.53 & 1.22 & 472 \\
$\# 10$ & 1.04 & 1.06 & 480 \\
$\# 13$ & 0.42 & 1.01 & 378 \\
$\# 17$ & 0.75 & 1.02 & 258 \\
Step 3 (\#24) for comparison & 0.85 & 0.91 & 359 \\
\hline
\end{tabular}



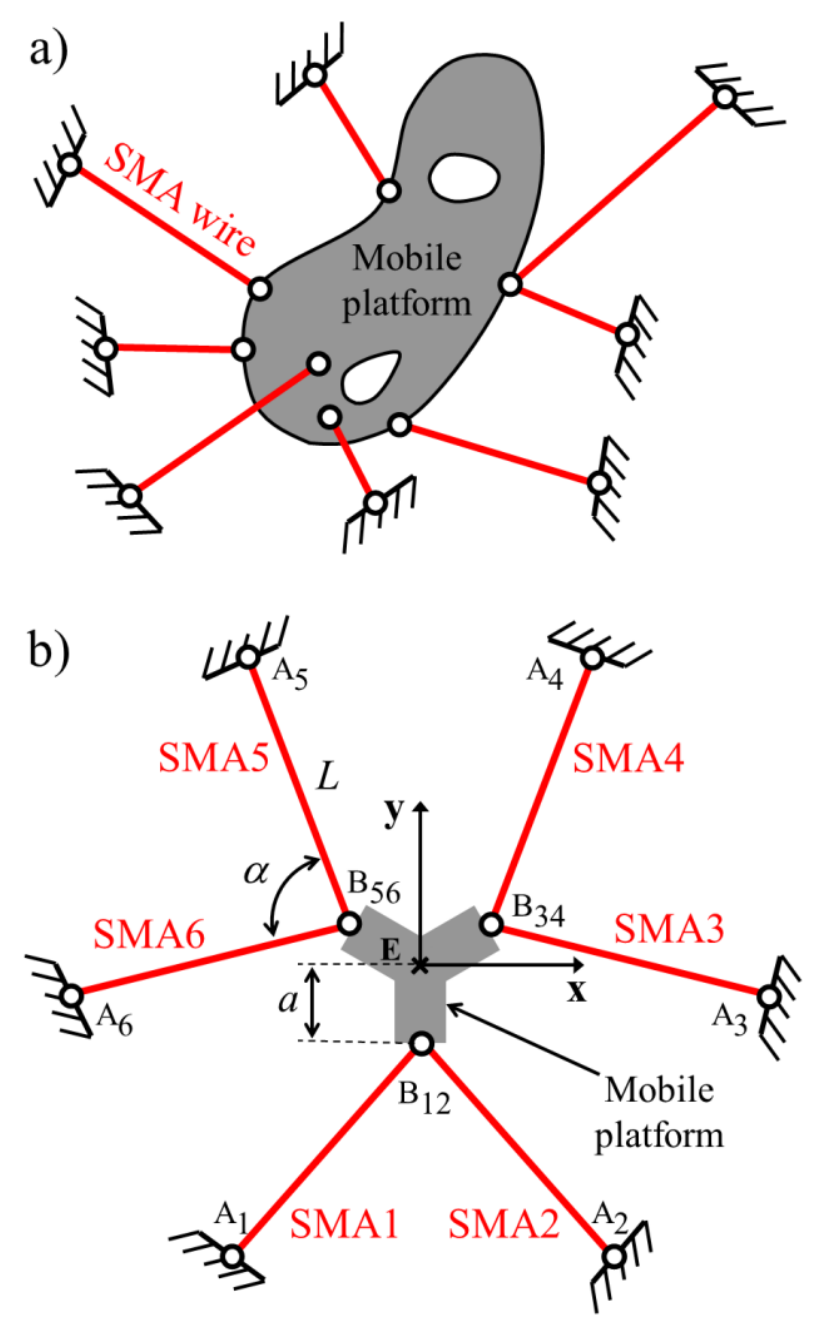

Figure 1. a) Schematic view of a mobile platform connected to several SMA wires, b) plane system studied. Output parameters are the rotation of the platform and the in-plane translation of point $\mathrm{E}$ as a function of the thermal activation of the SMA wires. 

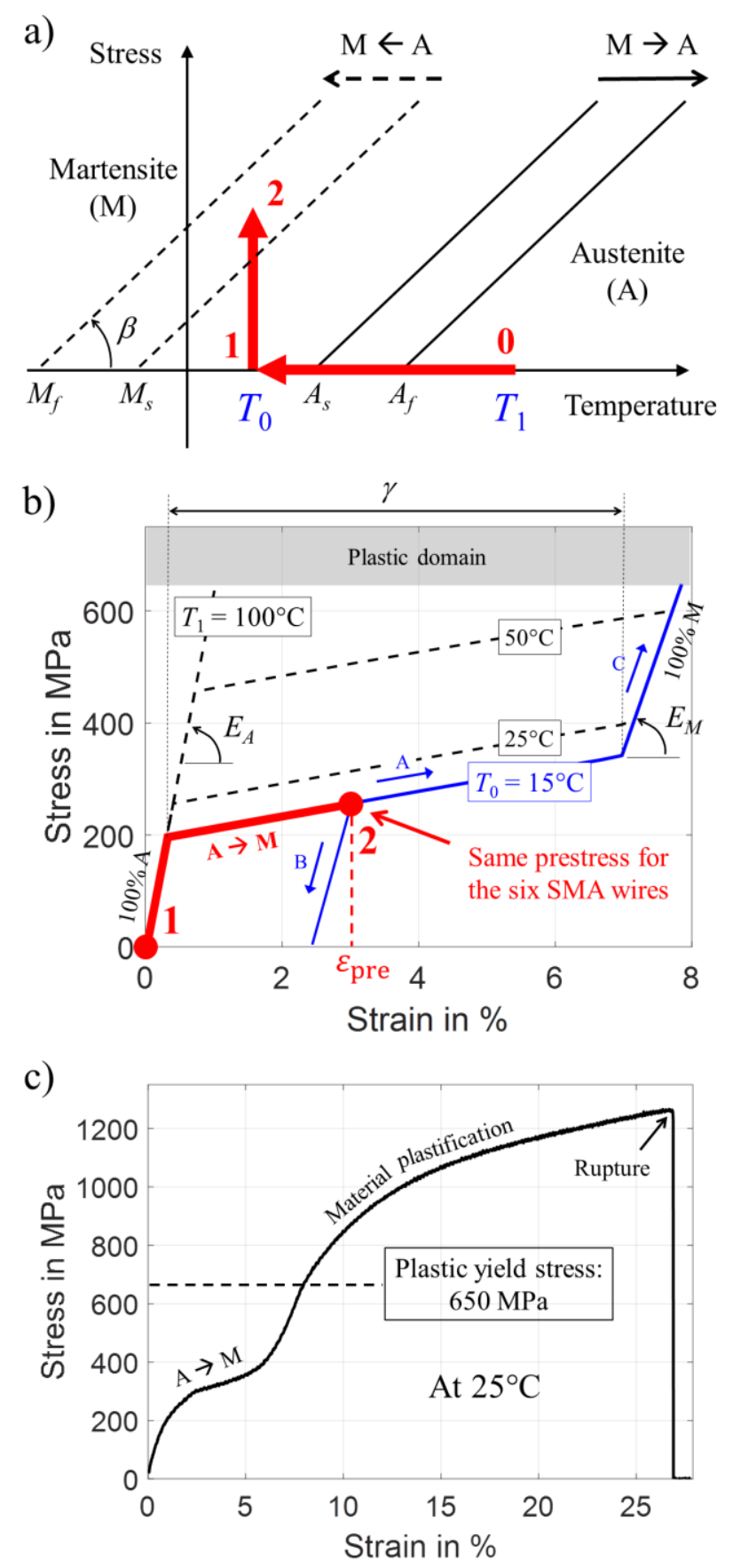

Figure 2. a) Simplified state diagram of a SMA wire in tension. The first three steps of the procedure are numbered 0, 1 and 2. Step 2 corresponds to the state of the six SMA wires before starting a thermal activation sequence. Due to the symmetry of the mechanical system, there is no movement of the platform from Step 0 to Step 2; b) model of the mechanical response of the SMA wires in tension; c) experimental stress-strain curve of a Ni50.8-Ti49.2 (at.\%) SMA wire, $1 \mathrm{~mm}$ in diameter, until rupture. 


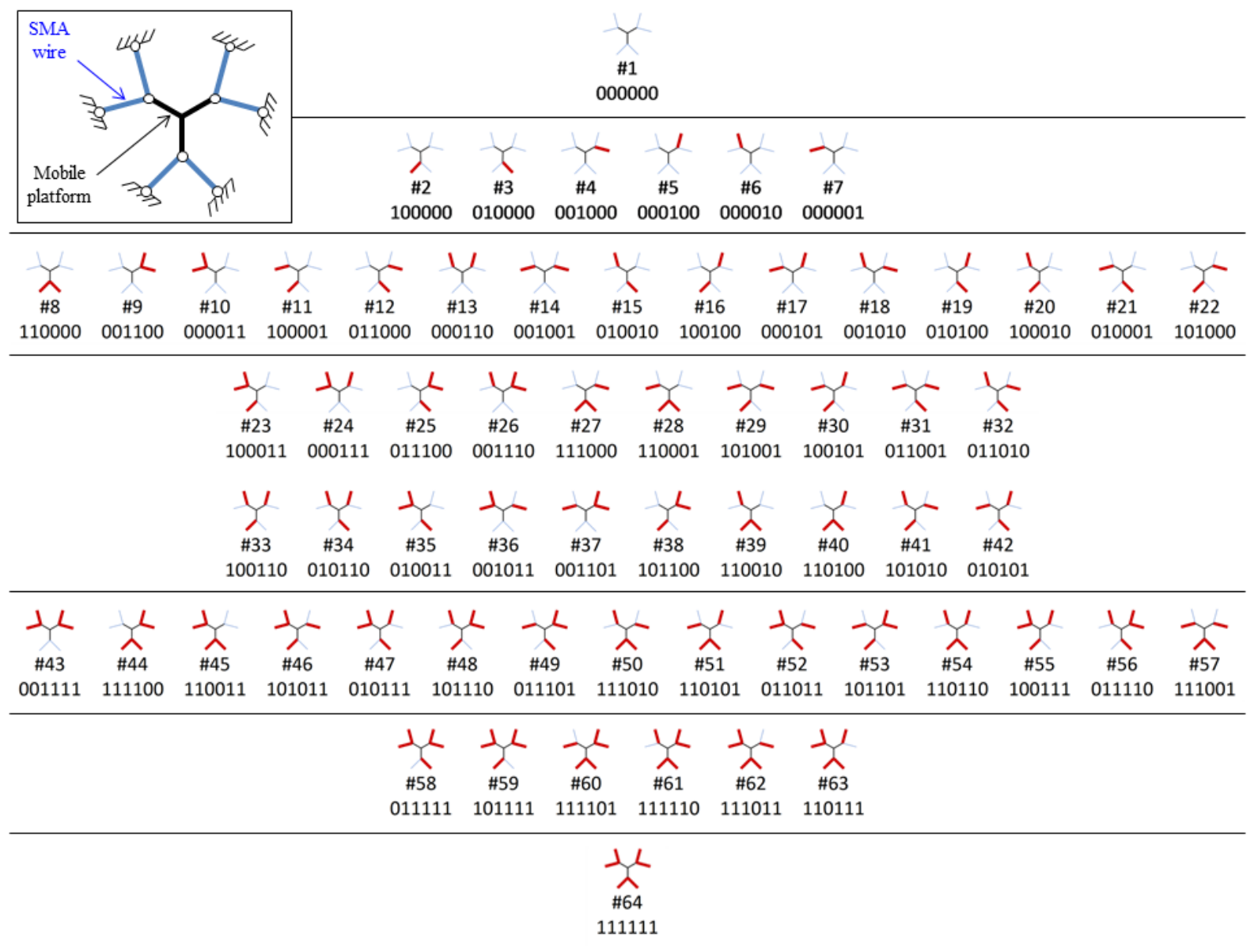

Figure 3. Various heating configurations of the six SMA wires. Red bold lines correspond to wires at activation temperature $\left(T_{1}\right)$; blue lines correspond to wires at ambient temperature $\left(T_{0}\right)$. Each configuration is identified by a six-digit binary number corresponding to the thermal state of the wires, for which " 0 " and " 1 " correspond to $T_{0}$ and $T_{1}$ respectively. 

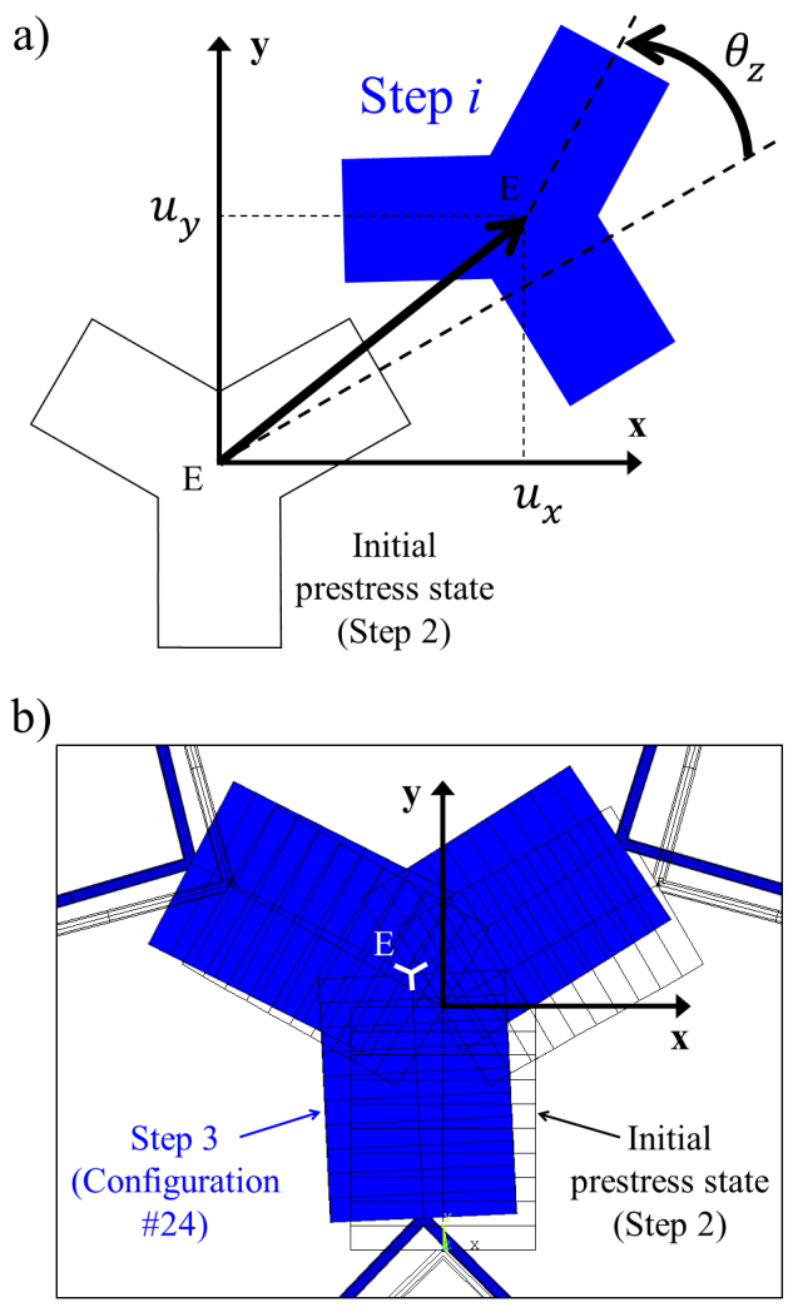

Figure 4. Movement of the mobile platform: a) definition of the in-plane translation $\left(u_{x}, u_{y}\right)$ and the rotation $\theta_{z}$ of the platform, b) example of position in real scale obtained by finite element simulation, for $\alpha=90^{\circ}, \varepsilon_{\text {pre }}=3 \%$ and Configuration \#24 applied at Step 3. 
a)

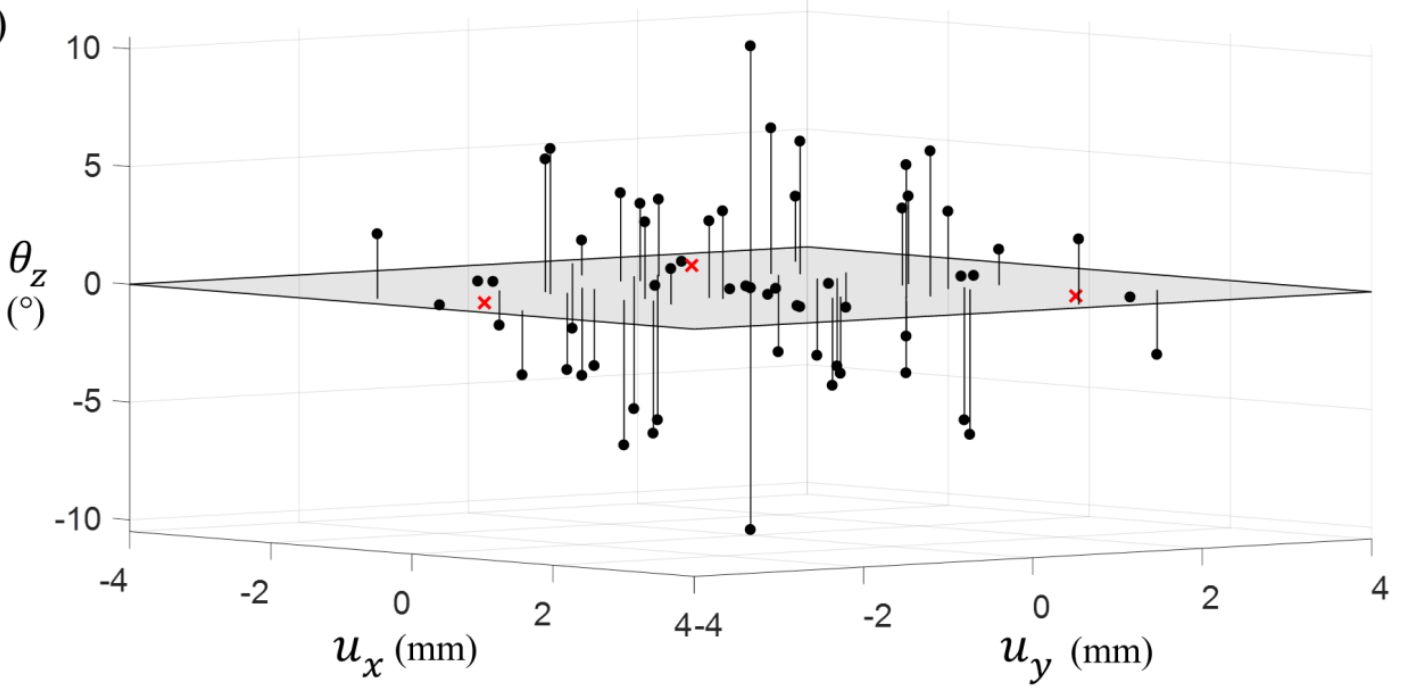

b)

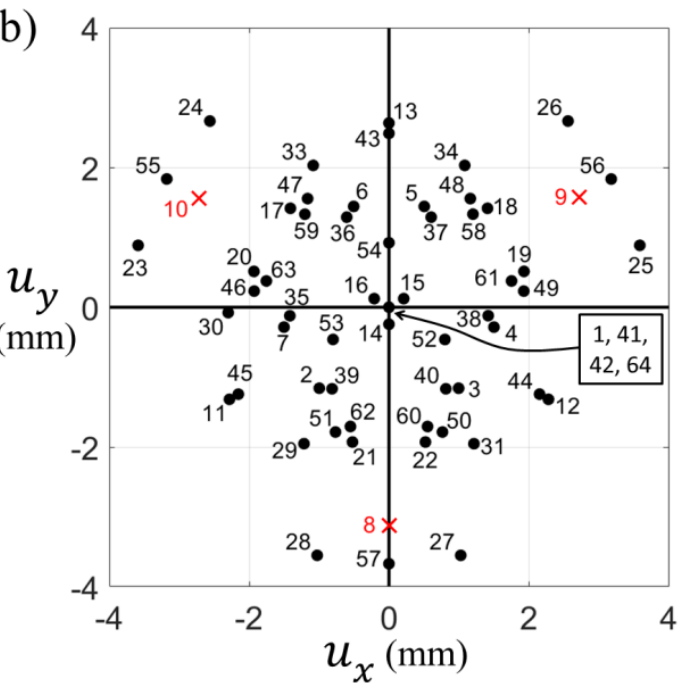

c)

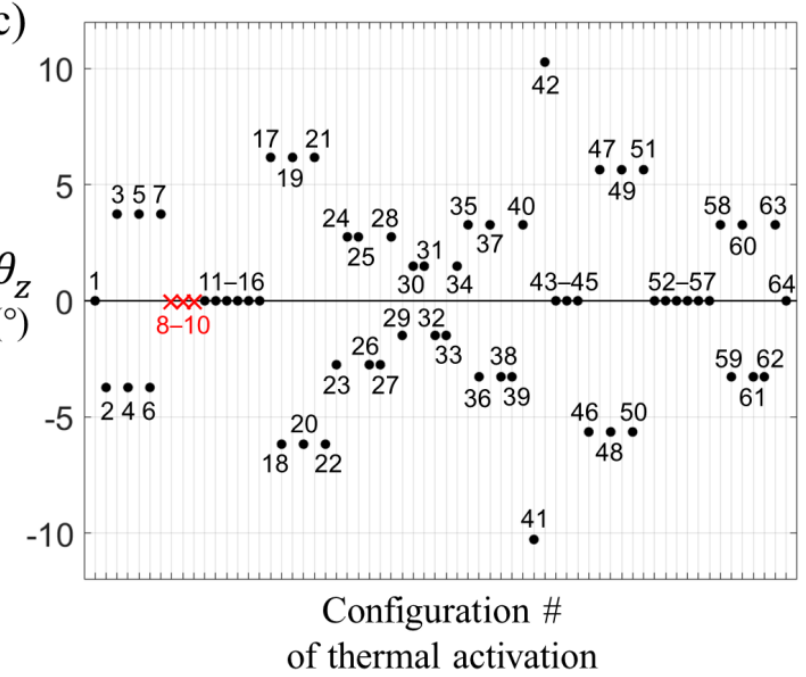

Figure 5. a) Movement of the mobile platform for $\alpha=90^{\circ}$ and $\varepsilon_{\text {pre }}=3 \%$ for different heating configurations at Step 3. Each point is defined by the in-plane translation $\left(u_{x}, u_{y}\right)$ of point $\mathrm{E}$ and the rotation $\theta_{z}$ of the platform. Red crosses correspond to configurations for which negative stresses are calculated in at least one SMA wire, meaning that these configurations are not valid; b) same in projection onto plane $\left.\left(u_{x}, u_{y}\right), \mathrm{c}\right)$ rotation $\theta_{z}$ of the platform.

Numbers refer to the heating configurations in Figure 3. 


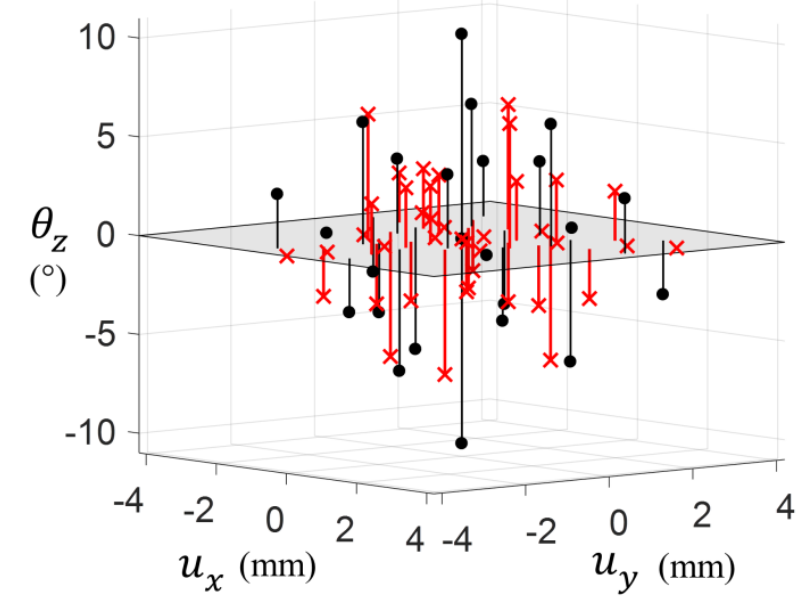

Figure 6. Overheating of the SMA wires leading to numerous non-valid configurations: same plot as in Figure 5-a, with the activation temperature increased until a full return to the austenitic state of the activated wires is achieved. Red crosses correspond to heating configurations for which stresses are negative or exceed the plastic yield stress of the SMA (non-valid configurations). 

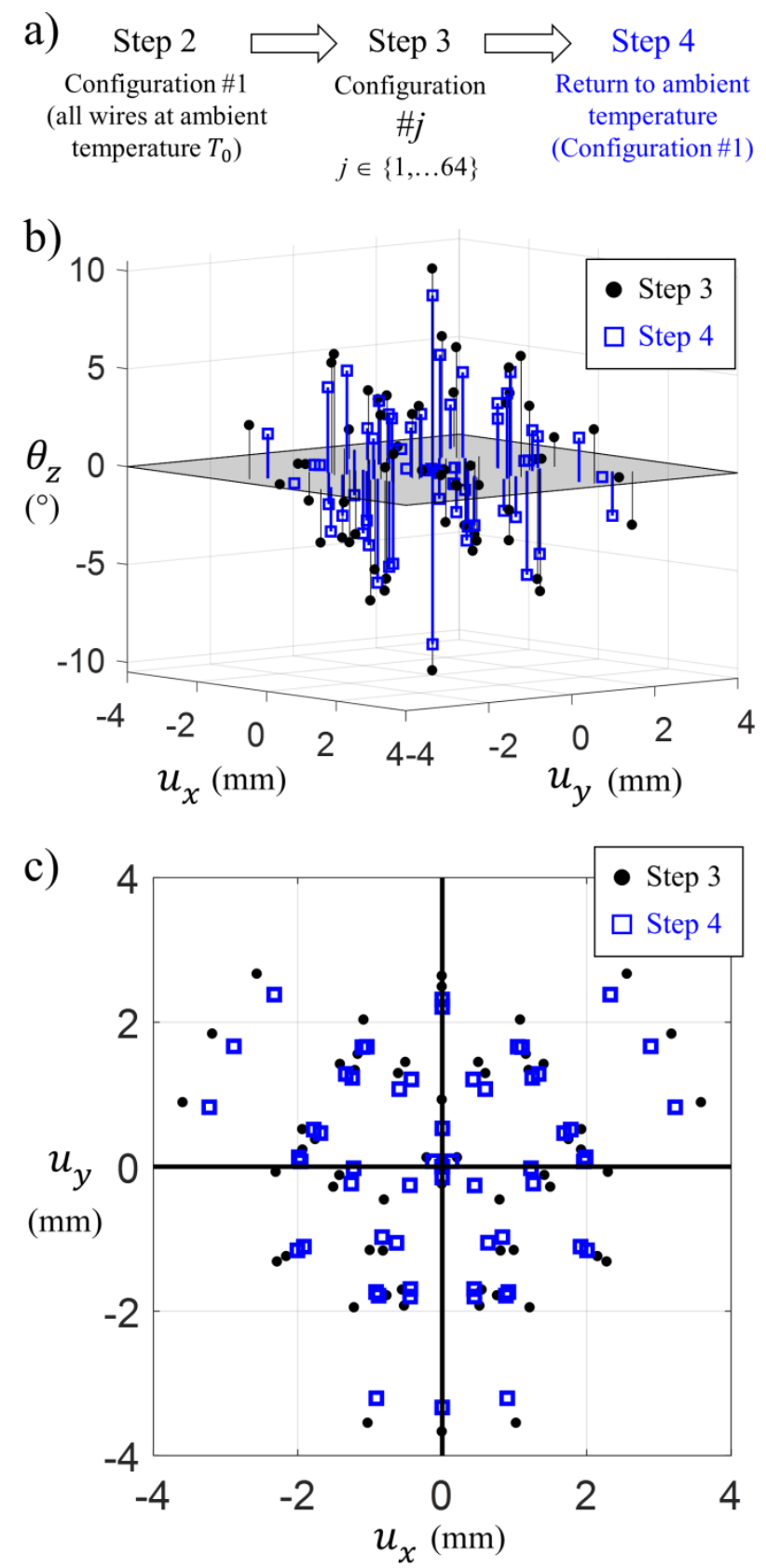

Figure 7. Platform movement is partially preserved when thermal activation is halted: a) thermal activation sequence considered, b) and c) same plot as in Figures 5-a and b. Dots and squares correspond to Steps 3 and 4 respectively. 

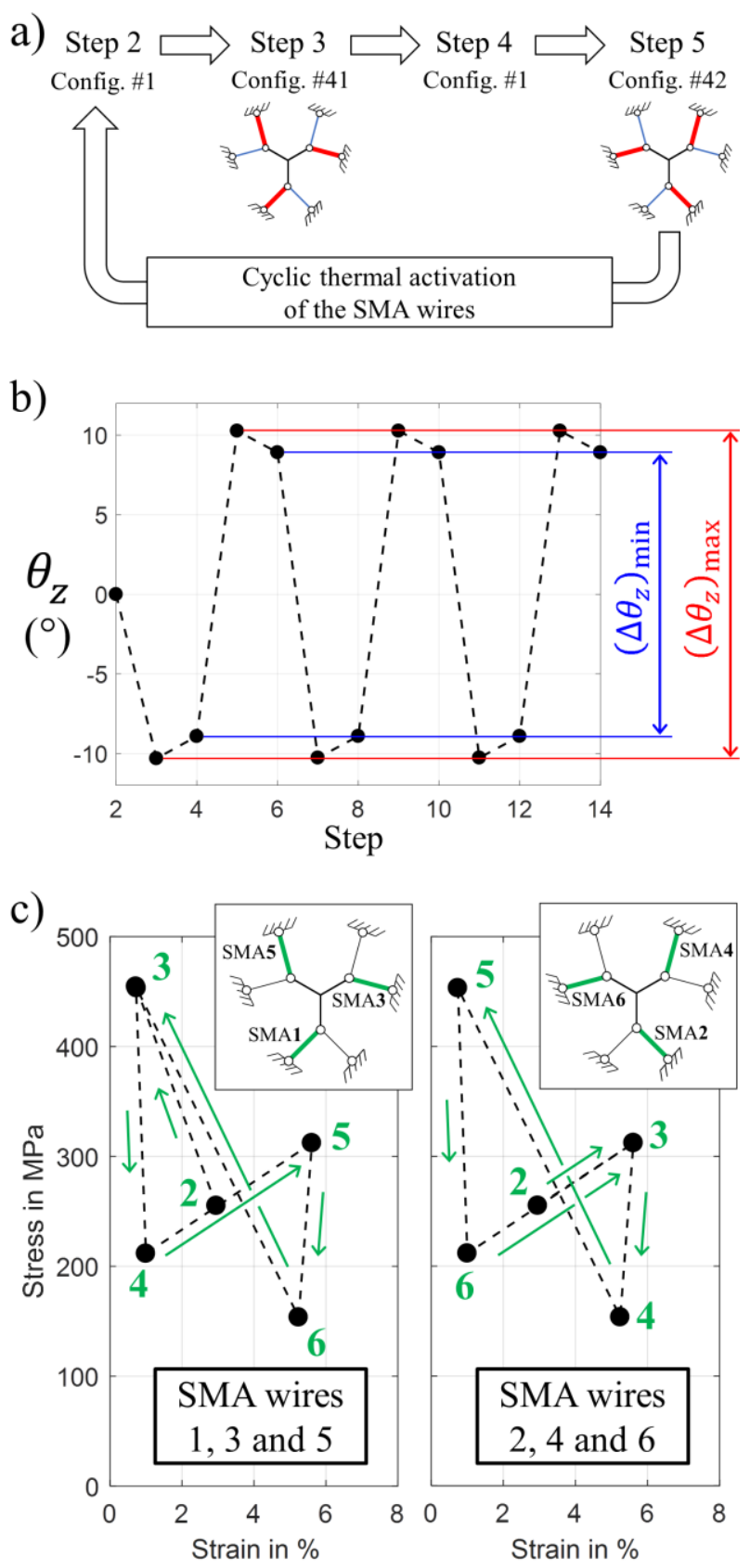

Figure 8. Creation of cyclic rotation by alternating Configurations \#41 and \#42 with intermediate returns to ambient temperature: a) thermal activation sequence considered, b) variation in rotation $\theta_{z}$ from one step to the next for $\alpha=90^{\circ}$ and $\varepsilon_{\text {pre }}=3 \%$, c) corresponding variation in stress and strain in the SMA wires. 
a)

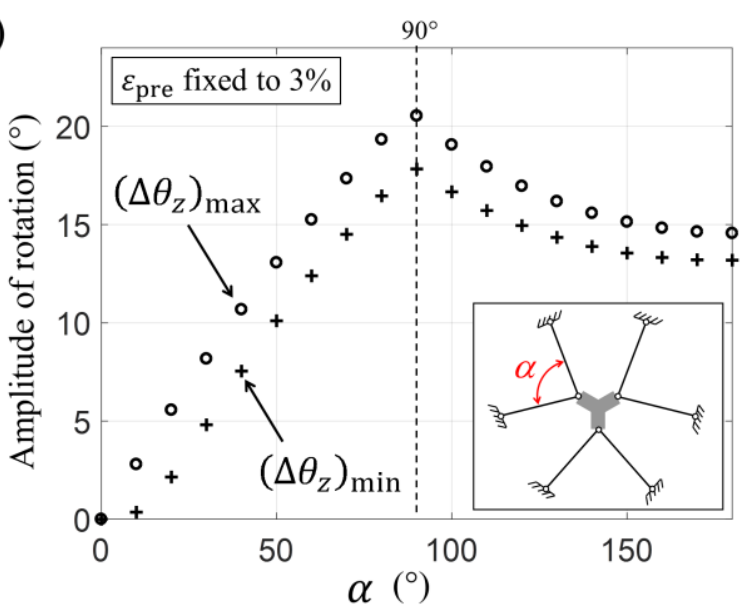

b)

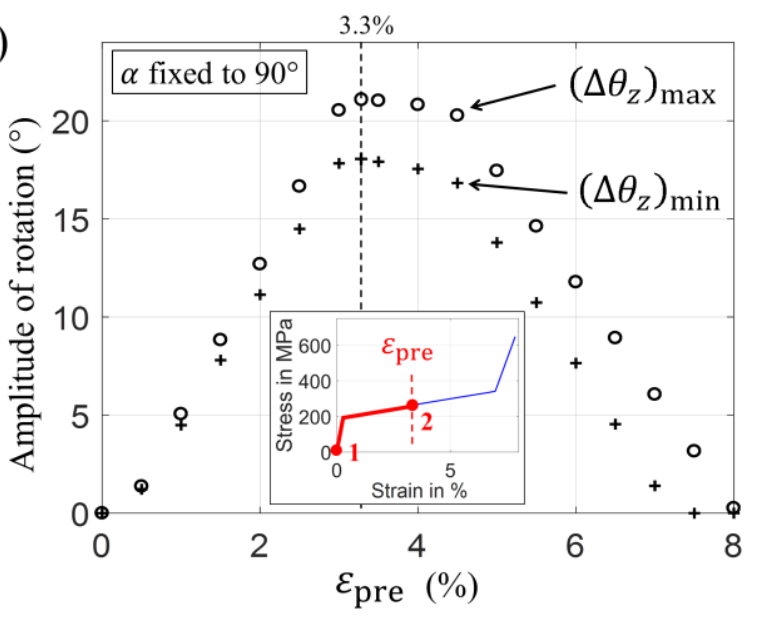

Figure 9. Amplitude $\left(\Delta \theta_{z}\right)_{\max }$ of rotation obtained by alternating Configurations \#41 and $\# 42$ as in Figure 8-a: a) as a function of angle $\alpha$ for $\varepsilon_{\text {pre }}=3 \%$, b) as a function of $\varepsilon_{\text {pre }}$ for $\alpha=$ $90^{\circ}$. Amplitudes $\left(\Delta \theta_{z}\right)_{\min }$ between intermediate returns to ambient temperature are also plotted. See Figure 8-b for the definition of $\left(\Delta \theta_{z}\right)_{\max }$ and $\left(\Delta \theta_{z}\right)_{\min }$. 

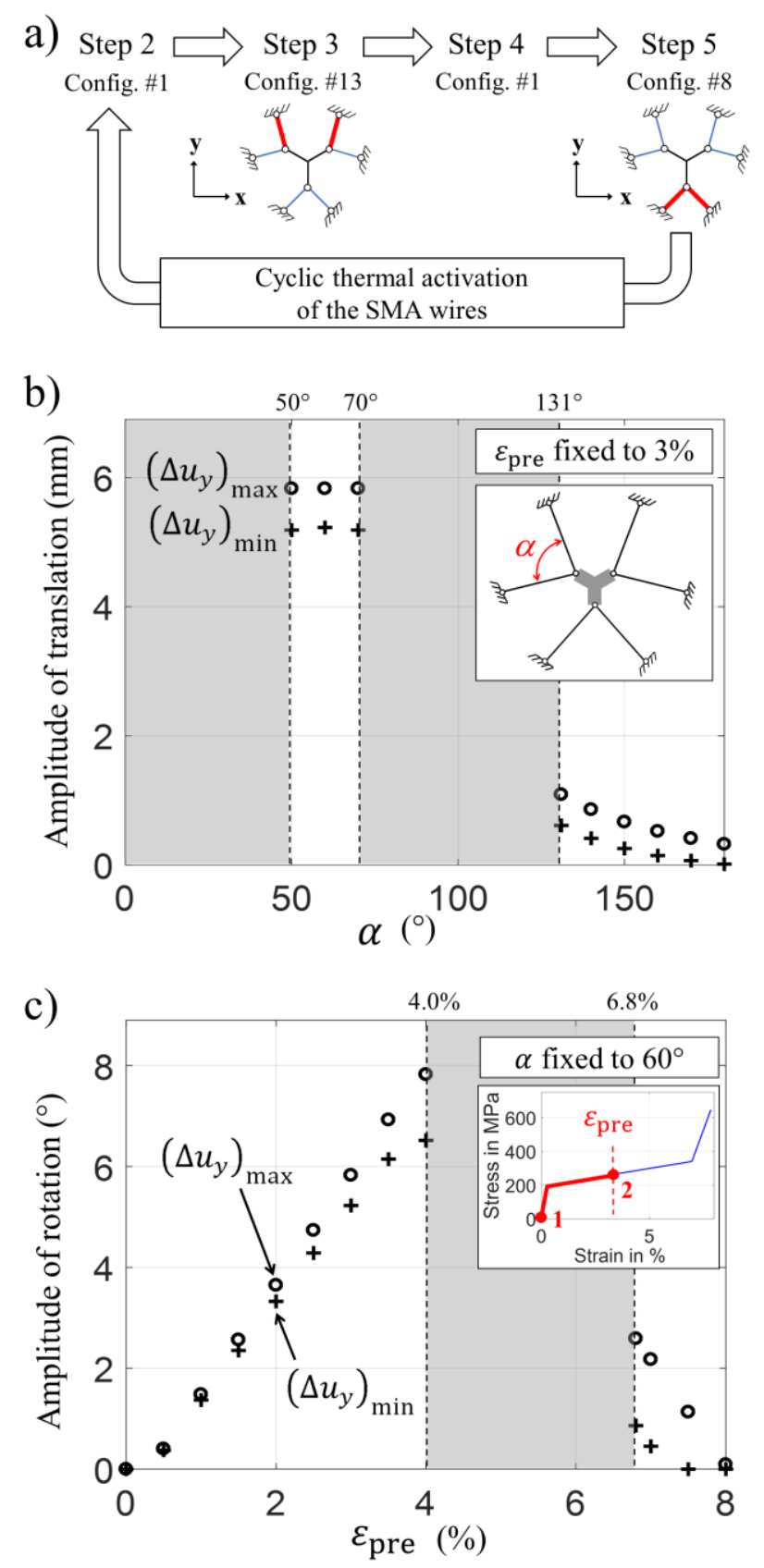

Figure 10. Cyclic translation obtained by alternating Configurations \#8 and \#13: a) thermal sequence considered, b) translation amplitude $\left(\Delta u_{y}\right)_{\max }$ as a function of angle $\alpha$ for $\varepsilon_{\text {pre }}=$ $3 \%$, c) same as a function of $\varepsilon_{\text {pre }}$ for $\alpha=60^{\circ}$. Amplitudes $\left(\Delta u_{y}\right)_{\min }$ between intermediate returns to ambient temperature are also plotted. Gray-shaded rectangles in the graphs correspond to non-valid situations. 

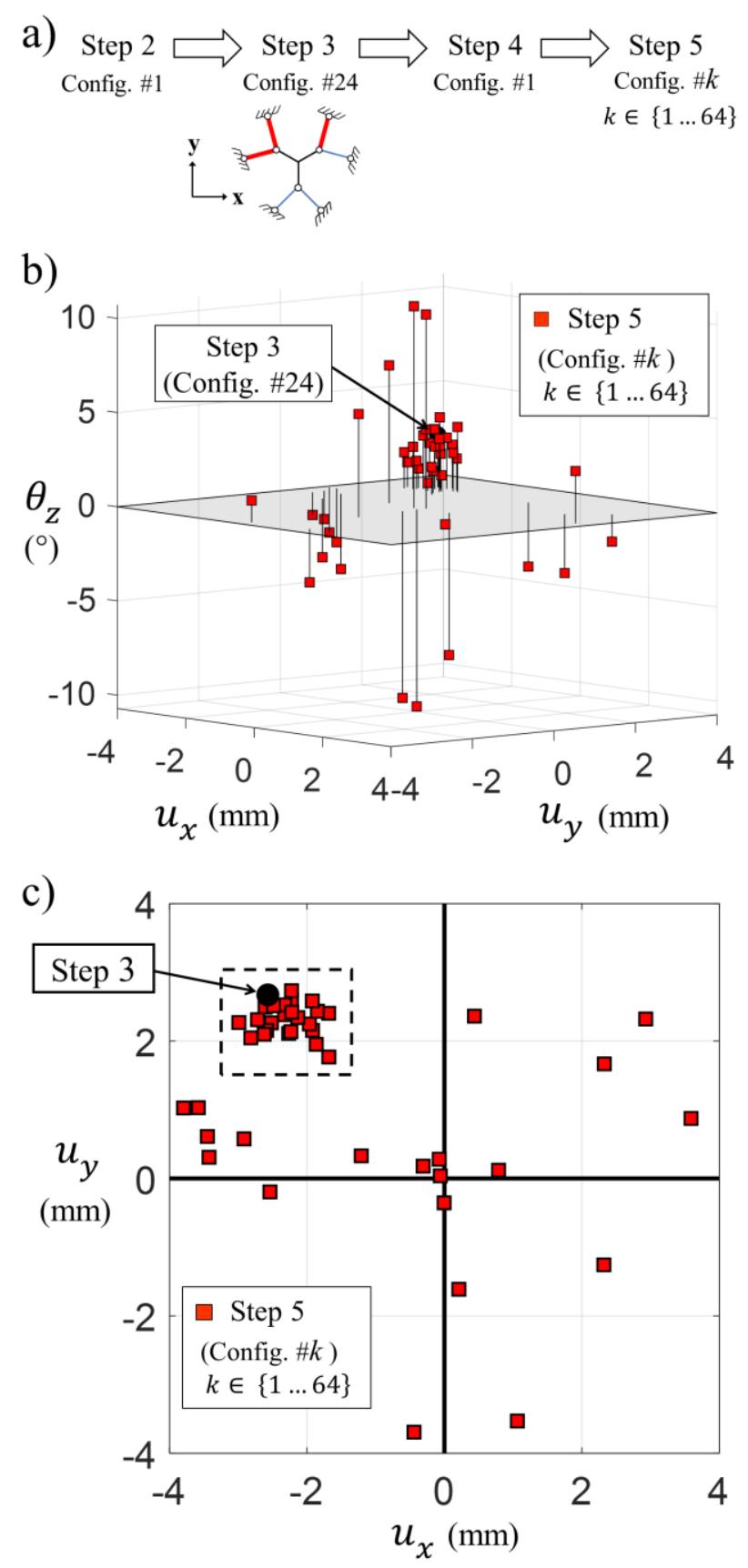

Figure 11. Evidence of an attraction effect: a) thermal activation sequences considered to observe the effect of Configuration \#24 in Step 3 on subsequent steps, b) and c) same plot as Figures 5-a and -b. Black dot and red squares correspond to Steps 3 and 5 respectively, for $\alpha$

$$
=90^{\circ} \text { and } \varepsilon_{\text {pre }}=3 \% \text {. }
$$




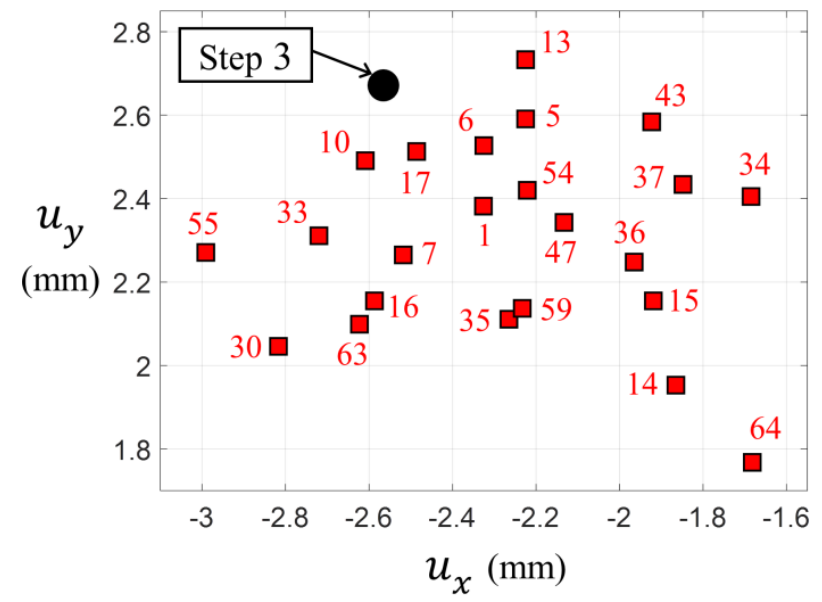

Figure 12. Close-up of Figure 11-c. Numbers refer to the configurations in Figure 3. 

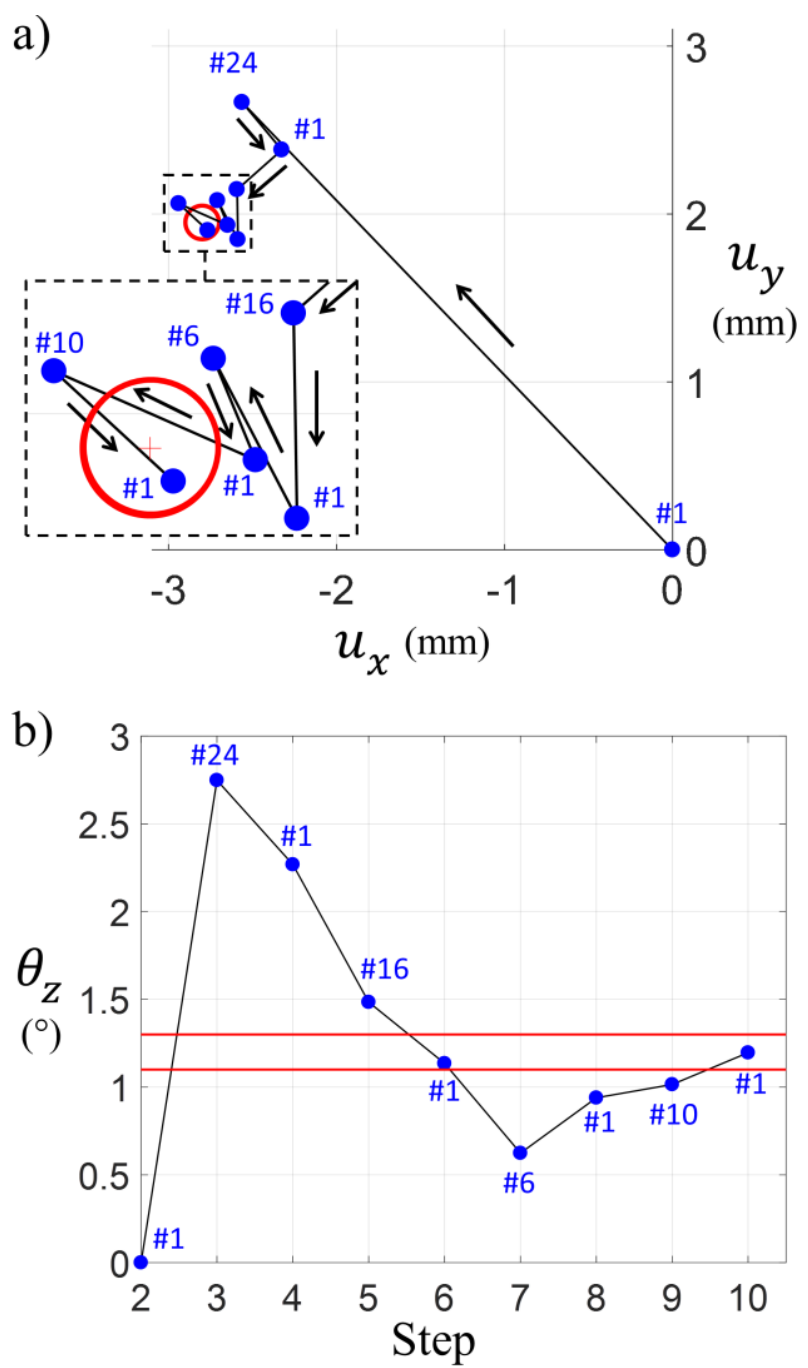

Figure 13. Example of a thermal activation sequence enabling a given platform position to be reached. The target was $\left(u_{x}, u_{y}, \theta_{z}\right)=\left(-2.80 \mathrm{~mm}, 1.95 \mathrm{~mm}, 1.2^{\circ}\right)$, with a precision of $0.1 \mathrm{~mm}$ and $0.1^{\circ}$ required for the translation and the rotation respectively, for $\alpha=90^{\circ}$ and $\varepsilon_{\text {pre }}=3 \%$.

The sequence was defined empirically, with the constraint of returning to ambient temperature (Configuration \#1) after each heating configuration. Configuration numbers refer to Figure 3. 